\title{
¿Fin de la preponderancia estratégica
}

\author{
norteamericana?
}

\begin{abstract}
A zais Joxe, de la Escueia Práctica de Altos Estudios (Sorbonne), es actualmente profesor investigador del Instituto de Estudios Internacionales de la Universidad de Chile. Durante varios años fue investigador del Centre d'Etude de Politique Etrangere de Paris. Entre sus publicaciones está El Conflicto Chino-Sovtético en América Latina, Arca, Montevideo, 1967 .
\end{abstract}

No es la correlación de fuerzas lo que crea el. equilibrio, sino la combinación de la correlación de fuerzas con las caracteristicas operacionales especificas del nivel de acción considerado.

generar a. beaufre, Slratégie de l'action.

Este trabajo toma en cuenta la evolución de un determinado número de factores estratégicos materiales en el curso del año 1968 y lo que va corrido de $19^{6} 9$ y de su consecuencia visible sobre el equilibrio de fuerzas en el seno del sistema internacional. Nos hemos basado únicamente en los datos publicados más recientemente, y éstos pueden muy bien no ser exactos, o incluso haber sido deformados deliberadamente para influir en las decisiones pendientes. No obstante, el concepto de preponderancia estratégica utilizado no se define tan sólo por el equilibrio estratégico y estadístico de las fuerzas; se refiere, por una parte -al nivel de los medios-, a la superioridad militar de los Estados Unidos sobre la Unión Soviética; es decir, principalmente, pero no exclusivamente, a la superioridad de los Estados Unidos en materia de armamento. Y se refiere, por otra parte. - il nivel' de la acción-, a la superioridad de los Estados Unidos sobre la Unión Soviética en términos de libertad de acción; o dicho de otro modo, a la capacidad de los Estados Unidos de elegir libremente el tema y el modo de confrontación local o global, en 
función de valores $y$ de órdenes de preferencia por ellos establecidos Finalmente, se refiere - al nivel de las concepciones estratégicas-, : la capacidad de los Estados Unidos para imponer a la urss su vocabula. rio y sus conceptos. Este último aspecto de la preponderancia nortea. mericana es considerado como el traslado de los otros dos al planc teórico.

Los profundos cambios de la coyuntura actual están relacionados con los recientes progresos realizados por la Unión Soviética en dos direcciones. La uRss ha decidido manifestar plenamente su presencia militar en las dos dimensiones del espacio geográfico, juridicamente no atribuidas a potencia politica alguna: el espacio exterior $y$ los mares abiertos (libres). No es lo suficientemente preciso decir que la Unión Soviética se propone adoptar un papel de potencia maritima. Su objetivo consiste en adquirir las prerrogativas y los medios de acción de una verdadera potencia mundial, rango al cuai su poderio económico, técnico y científico le permiter hoy día aspirar. ¿Ha logrado ya tal objetivo? ¿podrá mantenerse en dicho rango? o bien, ¿sus progresos actuales se verán absorbidos por un nuevo esfuerzo norteamericanó por conservar la supremacia? La interrogante queda planteada. Pero el año ig6 9 quedará en la historia como el año de la igualdad estratégica soviéticonorteamericana.

Pasaremos revista sucesivamente al efecto de este progreso soviético:

-en la evolución del equilibrio cualitativo y cuantitativo de los armamentos nucleares estratégicos sobre cohetes;

-en el despliegue de medios de intervención a gran distancia, esencialmente deruna flota de alta mar ultramoderna.

\section{LOS ARMAMENTOS NUCLEARES ESTRATEGICOS}

El gráfico anexo sirve de base a los comentarios sobre los armamentos estratégịcos. En el gráfico no figuran los bombarderos estratégicos del $\mathrm{SAC}^{*}$, ni sus equivalentes soviéticos, menos poderosos y se presenta globalmente de la manera siguiente:

* Strategic Air Command. 


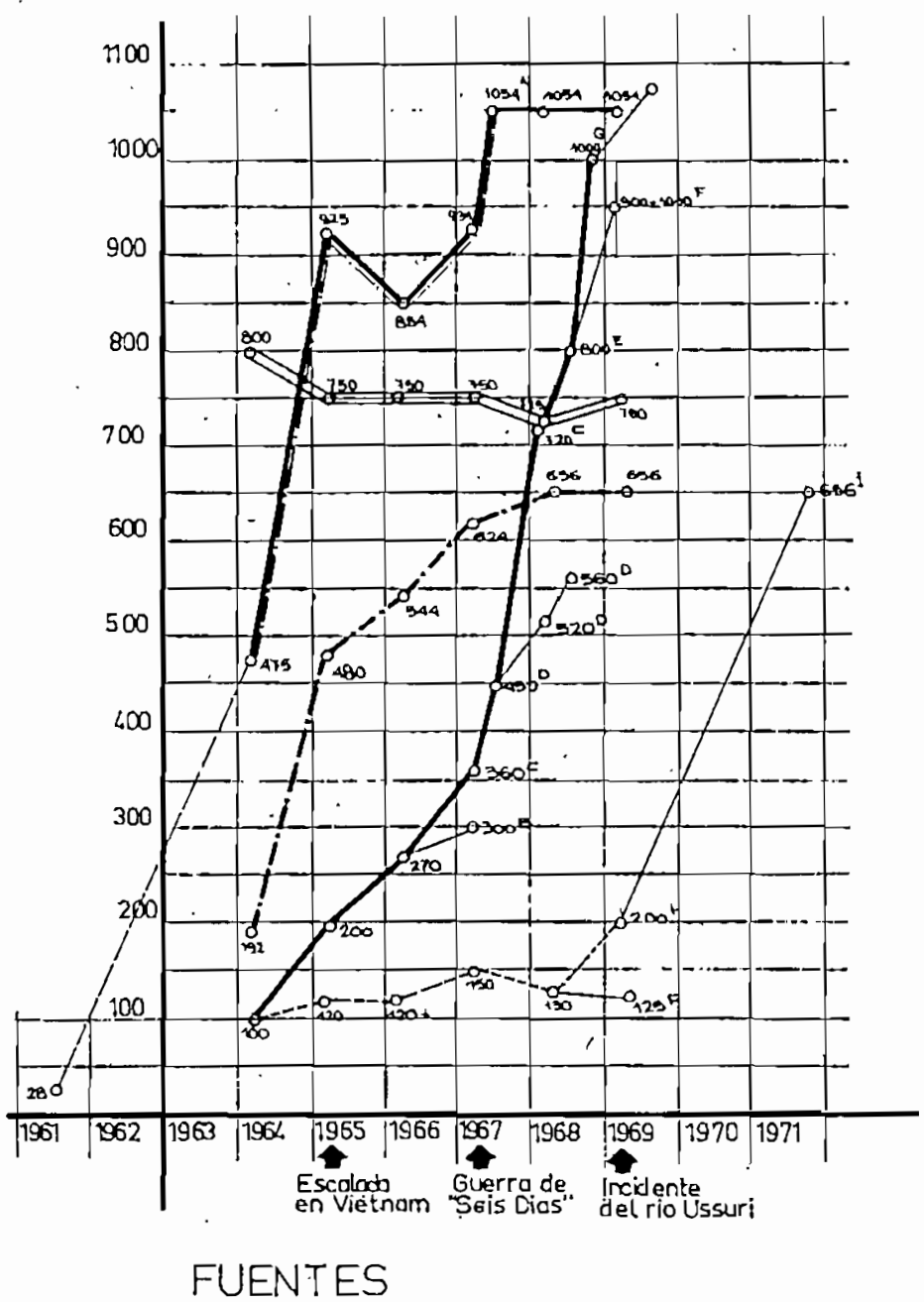
A . MC NAMARA, ESSENCE OFSTRATEGY P. 73
B. MILITARY BALANCE, 1966.67
C STRATEGY SURVEY, $1057 \mathrm{P} 22.23$
D MILTARY BAL_ANCE, 1967_68 P. 5
E MILITARY BALANCE, 1968_69 P. 5
F MILITARY BALANCE, 1968 _ 69 P.52
$G$ STRATEGY SURVEY, 1968 P. 29
H CSIS SOVIET SEA POWER, P.32
I CSIS SOVIET SEAPOWER, P. 34.35

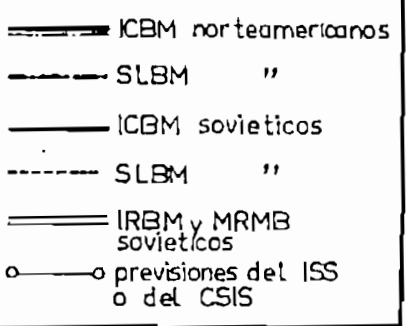


Del lado norteamericano: dos curvas que ascienden hacia un "techo" $y$ una vez alcanzado éste se in movilizan (los Polaris y los Minuteman).

Del lado soviético: dos curvas constantes: los IRßs (dirigidos sobre Europa principalmente) y los cohetes montados en submarinos.

Una curva de nivelación acelerada (ICBM).

Sobre esta base, se pueden reconstituir ciertos eiementos de la politica norteamericana y soviética en el curso de los últimos 5 años, describir la "maniobra de armamentos" de la Unión Sovićtica y sacar conclusiones sobre el momento actual relacionando la cuestión de los icbs. y lá de los aBM y los MrRv. La politica norteamericana ha consistido en fijarse un tope considcrado como razonable e incluso excesivo ${ }^{1}$ y de mantenerse en él durante dos años consecutivos, a pesar de la brusca aceleración soviética. La situación actual, por consiguiente, fue aceptada $o$, más aún, deseada por la administración Johnson; sin duda para facilitar, a faita de la paz en Vietnam, unas negociaciones que habrian sido útiles para las elecciones de 1968 ?! Es sabido que estas negociaciones, preparadas por los despliegues de ABis norteamericanos que permitian una "simetria cualitativa" y por las prucbas de arrv del mes de agosto de 1968 (Minuteman un y Poseidón) hábrían debido comenzar poco más o menos en el momento en que se produjo la crisis checoslovaca ${ }^{3}$. En esta situación la rentabilidad política de cualquier negociación con la uRss desapareció. Este conlratiempo permitió a los soviéticos continuar su progreso.

Analicemos sucesivamente la curva de los ICBM y los SLBM soviéticos y las

${ }^{1}$ Cr. MeNamara: The Essence of Security, p. 57: "Nucstra superioridad numerica actual sobre la Union Sovicica en cabezas nucleares es a la vez mayor que la que habiamos proyectado primitivamente g' superior a lo necesario".

${ }^{2}$ Según el Times del 14/3/1969, fuc anmbièn la proximidad de eslas negociaciones to que impulsó a : Mícivamara a aceplar como elemento negociable la construcción por los Estados Unidos de los ABм que èl mismo rechazara en enero de : g68.

${ }^{3}$ La decisión soviética de intervenir en Checoslovaquia fue tomada también por razones de equilibrio estratégico global. Si perdian el control de las montañas checas, perdian al mismo tiempo el control de los radares de alerta y un espacio gcográfico que por su posición en el corazón de Europa represenla la vign maestra estratégico del sistema sovićtico. El debilitamicnto del dispositivo de disuasión basado en el papel de rehén desempeñado por Europa occidental trastornaba la delicada relación cntre los dos sistemas de disuasión: sovićtico y norteamericano. 
Alain Joxe / ¿Fin de la preponderancia estratégica norteamericana?

curvas Minuteman-Polaris de los Estados Unidos en función de lo que se sabe sobre los otros sistemas de armas estratégicas:

\section{$1^{\circ}$ LA UNION SOVIETICA}

a) Los cohetes ICBM

El progreso de los soviéticos va acompañado de un efecto de sorpresa 4 Se ha hecho figurar en ese cuadro, basado en los datos publicados por el Instituto de Estudios Estratégicos de Londres, no solamente el estado real de los despliegues soviéticos, sino también los pronósticos establecidos cada año en el curso del periodo de $1966-1969$. Podrá notarse que los pronósticos se han basado siempre, del lado occidental, en la prolongación de la tendencia de la curva; es decir, suponiendo la invariabilidad del potencial de producción en una fecha dada. A comienzos de 9666 , se pronosticaba por consiguiente que la uRss pasaria de 270 a 300 ICBM, o dicho de otro modo, que la disminución del crecimiento, percibida entre 1965 y r 966 , iba a proseguir, pudiendo dicha disminución aparentemente estar relacionada con restricciones presupuestarias consecutivas al aumento de la ayuda proporcionada a Vietnam.

Pero, por el contrario, la tendencia se mantiene, e incluso aumenta, en el curso de 1967 , lo que trae aparejado nuevos pronósticos basados en la curva ascendente media de los 3 últimos años. Se preveia entonces que la U.R.S.s. poseeria 560 гсвм hacia mediados de Ig68. Ahora bien, la Unión Soviética habia alcanzado en esta fecha la cifra de 800 усвм. Incluso la última estimación de 900 a 1.000 para principios de 1969 ha sido ampliamente superada, dado que la cifra de 1.000 fue alcanzada ya en el mes de septiembre de 968 . Hay muchas posibilidades de que el número de los ICBM soviéticos sea hoy en dia superior al de los Estados Unidos.

El significado politico de la maniobra de armamentos soviética, puede calificarse de respuesta indirecta a una determinada política agresiva de los Estados Unidos.

En efecto, la marcha general de esta curva indica claramente que la capacidad de despliegue de iсвм pasó bruscamente, hacia comienzos de 1967 , de un centenar por año a 350 por año. Esto obedece sin duda a la puesta en marcha de nuevas unidades de producción en serie. Semejante incre-

4 Contrariamente a lo que indica Wolfe, Euolution of Soviet Military Policy, p. :1, nota 5 , la aceleración no fue prevista por Iss, MB $1967-68$, p. 5 . 
mento de la capacidad de producción debe corresponder a una decisión tomada dos años antes, y por lo tanto aproximadamente en I 965 , año que vio el comienzo de la escalada en Vietnam. Puede considerársela como una consecuencia de la decisión norteamericana de intervenir directamente en Vietnams. Se apreciará igualmente que el comienzo de la aceleración de los despliegues corresponde a la guerra árabe-israeli "de los seis dias",. y que el despliegue no ha sido disminuido en absoluto ante la apertura de las negociaciones de Paris sobre Vietnam. Puede decirse que la decisión de incremento rápido fue tomada como una de las respuestas al aumento de la intervención norteamericana en Vietnam; que la decisión de despliegúe corresponde (tal vez accidentalmente) a la guerra de los seis dias, y que el mantenimiento del crecimiento rápido pesa sobre las negociaciones relativas a Vietnam.

La maniobra soviética forma parte de una estrategia doblemente indirecta encaminada a sacudir a los Estados Unidos, no en el plano local ni incluso en el plano diplomático, sino arremetiendo contra las raices mismas del sentimiento de seguridad construido durante ocho años por la doctrina McNamara, y basado, en último análisis, con respecto a la opinión pública, en la "overkill capability". (Capacidad de matar más de una vez la población soviética, en un sentido estadistico).

La definición estratégica de la maniobra es la de una ofensiva frontal dirigida sobre todos los puntos en que la superioridad norteamericana parecia establecida. El esfuerzo armamentista soviético es tanto más marcado cuanto que no se trata solamente de la aceleración del despliegue de un tipo ya conocido, el Iсвм Savage (comienzo de despliegue: i 966 ; combustible: probablemente sólido; alcance: 6.000 millas; cabeza: I megatón), sino del despliegue desde el comienzo de 1969 ó fines de 1968 de una nueva arma de caracteristicas más avanzadas: el ss -9 (combustible: sólido; alcance: intercontinental ${ }^{\sigma}$; cabeza: dotada de $3^{\top}$ ó $5^{\text {s cabezas }}$

$s$ Esta es la interpretación de Thomas W. Wolfe, Evolution of Soviet Military Policy, Rand Paper, $N^{\circ}$ P. 3773, febrero ig68, pp. 7-8, iss, ss 1968 , p. 25, fija la decisión en la misma fecha, pero haciendo de ella más bien una consecuencia directa del derrocamiento de Jruschov y del aumento del poder de los militares; o dicho de otro modo, esta obra ve en la decisión más el efecto de movimientos internos en la URss, que la consecuencia directa de la política norteamericana. Parece más exacto decir que Jruschov fue eliminado como obstáculo a una politica militar que la agresividad creciente de los Estados Unidos después del asınto del Golfo de Tonkin hacia muy necesaria.

- Según Time, 27 de junio de 1969 , p. 12, el ss-9 no habia alcanzado nunca más de 3.200 
Alain Joxe / ¿Fin de la preponderancia estratégica norteamericana?

independientes de 5 megatones cada una, o sea $15^{-25}$ megatones en total) que forma ya parte de la generación de los cohetes equipados con'Mirv. El ss-9 está emplazado en "silos" "muy' protegidos y separados por distancias tales que una cabeza nuclear norteamericana nó puede destruir más de un ss-9 a la vez. Las cabezas múltiples fueron ensayadas en agosto de I $6^{68^{9}}$, al mismo tiempo que los MIRv norteamericanos, pero los soviéticos disponian de 200 ejemplares operacionales hacia el mes de abril de $1969^{10}$, en tanto que los Poseidón y los Minuleman in no están desplegados y sin duda no serán operacionales añtes de mediados de $1971^{11}$. Los cohetes de la generación anterior, con combustible líquido "stockabie" (almacenable) permanecen en servicio, y están dotados de cabezas cuya potencia varía

millas antes de las prucbas de agosto de 968 , que demostraron que dicho cohete podia alcanzar ahora "la mayor parte del territorio de los Estados Unidos".

7 "Busload of Megatons", Time, 27 de junio de : 969 , p. 12.

"R. E. Hunter, "The aвм, President Nixon's Safeguard", World Today, mayo, 1969 p. 193.

9 Iss, ss 1968, P. 25; Time, 27 de junio de ig69, loc. cil., introduce una distinción nueva inspirada por el Departamento de Defensa, $y$ vuelta a utilizar por M. Tatu, Le Monde, 26 de julio de rg6g, p. 1, entre los "Murv" que equipan a los Poseidón y los Minutemann m, y los "xtrv" que equipan a los ss-9 soviéticos. Los "MrRv" norteamericanos. (Múltiple Independently Targetable Reentry Vehicle) son cabezas nucleares que el ingenio portador puede sembrar una por una a todo lo largo de su itinerario final sobre el territorio enemigo; cada cabeza dispone de un sistema de guia zutónomo $y$ el ingenio portador puede ćl mismo variar, de trayectoria entre cada "puesta". Los "MRv" soviéticos (Múltiple Reentry Vericle) en vias de despliegue, son fuegos de artificio mucho más sencillos: llegado a una distancia conveniente, el SS-9 larga de un solo golpc tres cabezas de 5 megatones, estando la dispersión de las cabezas calculada de forma de habérselas económicamente con los emplazamientos norteamericanos de Minuteman. El Secretario de Defensa, M. Laird, dijo que los rusos no eran capaces de lanzar sirvv, pero en el curso de una conferencia de prensa de la segunda quincena del mes de junio, el Presidente Nixon admitió que los sovièticos habian puesro a punto "un cierto sistema de control" para sus Mrv. La única diferencia notoria seria pues que los MIRv norteamericanos podrán ser largados sucesivamente, en tanto que los $M r v^{\prime}$ sovièticos no pueden ser largados más que simultáneamente. Los dos sistemas de MIRV parecen adaptarse respectivamente a los sistemas de. ABM que deben pénetrar y saturar. La red ABM soviética seria desbaratada por los MfRv nortemericanos si es cierto que ella está concebida como basada en el control de los itinerarios balisticos probables de los ICBMr norteamericanos hacia los objetivos soviéticos, púesto que el itinerario de los nuevos cohetes norteamericanos seria aleatorio.

${ }^{10}$ R. E. Hunter, ibid., p. $19^{8 .}$

"Time, loc. cit. 


\section{F S T U D I O S I N T ER N A C I O N A L E S}

entre 5 y 20 megatones $^{12}$, pero su número exacto no ha sido publicado. Sobre la base de estos datos, dificilmente puede intentarse una evaluación global del potencial de los ICBM soviéticos en términos de megatones que pueden ser lanzados, pero es preciso señalar que el último fruto de los esfuerzos soviéticos, los $2005 s-9$, representan por si mismos más que todo el esfuerzo de despliegue desde 1967 . Se trata de un cambio del orden de magnitudes: desde 1967 , si se admite que todo el crecimiento del potencial soviético corresponde al tipo Savage, un aumento de 600 cohetes corresponde a un aumento de 600 cabezas y por consiguiente de 600 megatones. 200 cohetes $5 s-9$ representan un aumento de boo- 1.000 cabezas y por tanto de 3.000 a 5.000 megatones.

De este modo, según las declaraciones del Secretario de Defensa de los Estados Unidos ${ }^{13}$, la uRss alcanza la paridad en materia de ICBM, pero esto significa en realidad una superioridad. En materia de precisión, los soviéticos están por lo menos en paridad con los Estados Unidos. En cuanto al factor vulnerabilidad y concentración de los objetivos-recursos, éste juega contra los Estados Unidos, como lo demostraba McNamara hace varios años ${ }^{14}$.

\section{b) Cohetes lanzados desde submarinos}

El potencial soviético debe apreciarse igualmente tomando en cuenta los cohetes balisticos montados en submarinos. Estos últimos fueron durante largo tiempo de un modelo más antiguo que los Polaris: los primeros modelos no podian ser lanzados más que desde la superficie y tenian un alcance reducido; se trata de los Sark (400 millas de alcance, entrada en servicio en 1959) y los Serb (600 millas de alcance, entrada en servicio en 1961); ambos de combustible liquido ${ }^{15 l}$ Pero los cohetes Serb están continuamente en vias de perfeccionamiento, y, según ciertas fuentes, la nueva ver-

12 En todo caso, quedan en servicio tres tipos de lсвм de combustible liquido y almacenable, uno de 10 megatónes, pucsto en servicio en 1963 ; el segundo, el Sasin, de 5 megatones, puesto en servicio igualmente en 963 , $y$ un tercero de 20 megatones entrado en servicio en $: 965$, cuyos alcances respectivos son de $5.000,5.000$ y 10.000 millas.

13 Declaración Laird del 21 de marzo de 1969 , Keesing's Contemporary Archives 23290.

${ }^{14}$ Lzird recuerda que, según. McNamara, con 1.200 cabezas de a 1 megatón, los Estados Unidos pueden destruir el $45 \%$ de la población sovietica, mientras que con 200 cabezas de un megatón, la l'rss puede destruir el $55 \%$ de la población norteamericana.

${ }^{15}$ Iss. Military Balance, $1968-69$, p. 54 . 
Alain Joxe / ¿Fin de la preponderancia estratégica norteamericana?

sión, salida en 1968 , lograria realmente un alcance de I.500 millas náuticas y equiparia 7 submarinos nucleares a razón de $: 6$ por submarino, mientras que la versión más reciente alcanzaria incluso por lo menos 2.000 millas náuticas, según una declaración hecha en marzo de ig68 por el almirante S. Gorshkov. ${ }^{16}$; y equivaldrian por lo tanto a los Polaris $\mathrm{A}-2^{17}$. $\mathrm{Su}$ número total se venia manteniendo estacionario desde hace muchos años - aproximadamente 125 según el iss de Londres-, pero, de acuerdo con el reciente estudio del Centro de Estudios Estratégicos e Internacionales de Washington (Georgetown University), probablemente más cercano a la opinión de la marina norteamericana, hoy dia deberia calcularse un total de 200 cohetes de diversos tipos ${ }^{18}$, y tal vez 232. Los expertos piensan que el cohete equivalente al Poseidón, es decir, dotado de MIRv, debe hallarse desplegado a comienzos de la década del setenta, o a más tardar en 1975 .

Los submarinos portadores de cohetes son de diversos tipos, y más adelante volveremos a ocuparnos de la flota submarina en general. En lo concerniente a los submarinos portadores de proyectiles balisticos a propulsión nuclear, alcanzarian la cifra de $3^{8}$ a comienzos de $1969^{19}$. pero su número aumenta sin cesar debido a la construcción al ritmo de.un submarino por mes $^{20}$ (del último tipo, del cual se han desplegado 7 ejemplares últimamente). Pero es preciso señalar que el total de los submarinos a propulsión nuclear (portadores de proyectiles balisticos o no), se estimaba, en I 968 , en $50^{212}$ para comienzos de 1969 ; y que actualmente dicho número es estimado en $60^{22}$, o incluso $65^{23}$, lo que tenderia a indicar que el ritmo de

${ }^{16}$ Center for Strategic and. International Studies, Georgetown University, Soviet Sea Power, Washington, D. C., 1968, junio, Pp. 32-33.

17 Strategic Survey, t968, p. 24 , les atribuye sólo el alcance de los Polaris A-1, o sea 1.380 millas. Con ocasión de la presentación de este cohete en .Moscú en el curso del destîle del 7 de noviembre, se habia revelado que tenia la talla del cohete Poseidín, pero no necesariamente los mismos atributos (15s, ss 1967, p. 23).

2o csis, Soviet Sea Power, P. $3^{2}$.

19 iss, $1 \mathrm{M}$ 68-69, P. $5^{2}$.

20 Según las declaraciones oficiales norteamericanas, I' no de 5 por año únicamente, como escribe Martin Edmonds y John Skit, Current Suviet . Waritime Strategy; Internationâl Affairs (Londres), enero de 1969, p. 30 .

21ISs, MB $68.69 \cdot 52,3^{8}$ lanzadores de proyectiles balísticos, y 12 que no lo son.

${ }^{22}$ csis, Soviel Sea Pouser, p. 32.

23 Según una declaración hecha por el almirante Rickover en el curso de un informe ante 
despliegue es todavia más rápido que lo previsto. Como quiera que sea, el ritmo actual, teniendo en cuenta que más de un tercio de la producción de submarinos nucleares estarian destinados a convertirse en portadores de proyectiles balísticos, el número de los submarinos a propulsión nuclear podria pasar de los 100 mediados del año 1970 , y el número total de cohetes montados sobre submarinos soviéticos podria superar al total de los Polaris a fines de 1971, de mantenerse el actual tope de submarinos Polaris's.

La curva estacionaria de los cohetes sobre submarinos soviéticos ha comenzado pues repentinamente a elevarse con tanta rapidez como la curva de los ICBM en i 967 .

\section{c) Los cohetes ABM:}

Los soviéticos han aflojado su esfuerzo de instalación de los AB: ${ }^{12 s}$. Después de haber provocado en cierto modo a los Estados Unidos, parecen adherir plenamente a la teoria de McNamara y confiar en el desarrollo acelerado de su potencial de cohetes estratégicos para, a la vez, adquirir la capacidad de saturar toda defensa norteamericana y mejorar su propia capacidad de disuasión.

\section{$2^{\circ}$ LOS Estados UNidDOS}

a) Los cohetes IсBM

Nixon afirmó durante su campaña que la administración demócrata habia dejado que surgiera una brecha en materia de seguridad, security gap, al adoptar la doctrina de la paridad nuclear, comprometiéndose él mismo a restaurar la "superioridad" de los Estados Unidos. No se puede evitar, sin embargo, el considerar que la política norteamericana da pruebas de una cierta continuidad y que, de Johnson a Nixon, el estudio de la curva de despliegue norteamericano de Iсвм, la inmovilización de ésta so-

el Congreso el 23 de abril de 1969 y que no fue dada a la publicidad hasta el 22 de junio. Cf. "El almirante Ríckover critica severamente a! Pentágono", Le .londe, 25 de junio de ig6. p. 5 .

${ }^{24}$ CSIS, SSP, Pp. $34-35$.

25 iss, ss $: 968$, pp. $24-25$. 
Alain Joxe / ¿Fin de la preponderancia estratégica norteamericana?

bre maximos numéricos corresponde a una pausa o espera concertada, la cual todavia no ha vuelto a ser cuestionada.

Después del ligero "descenso" de dicha curva ocurrido el año 1966 , que correspondió a la descalificación de los cohetes de combustible liquido de la generación anterior (Atlas y Titan 7), los cohetes intercontinentales norteamericanos están todos hoy dia protegidos en silos, y son de una rápida entrada en fuego. Seis escuadrones de proyectiles balisticos Titan 2 (de combustible liquido, 9.000 millas de alcance y dotados de cabezas'de más de 5 megatones) que entraron en servicio en 1963 , permanecen desplegados. En la segunda mitad de 1968 habia 1.000 Minuteman, cohetes de combustible sólido, protegidos en silos, $65^{\circ}$ de los cuales eran todavía del tipo Minuleman I (6.500 millas de alcance, cabezás de más de un megatón, puesto en servicio en 1962 ), pero poco a poco, desde $: 966$, los Minuteman I han sido reemplazados por los Minuteman ir (alcance: 7.900 millas; cabezas de 2 megatones).

Los Estados Unidos, como lo señalara McNamara poco antes de su dimisión ${ }^{27}$, se fijaron un máximo muy largamente calculado y se han mantenido en él, absteniéndose de lanzarse al despliegue de los Minuteman II, dotados de MIRV (tres cabezas independientes de 1 megatón cada una). Pero esta abstención tal vez no sea ya enteramerite voluntaria.

Los Minuteman in fueron ensayados el 16 de agosto de $1968^{28}$, es decir, más o menos al mismo tiempo que el MrRv de que estaria dotado el ss-9 soviético. Mientras el ss-g ha pasado ya a la etapa de la producción en serie y del despliegue, el Minuteman ni aparece todavia en la fase del desarrollo, y es considerado como el sistema de arma de los años setenta. El Secretario de Defensa, Laird, decia en el mes de abril de 1969 que no se habia previsto aumento alguno del número de ICBM para el año en curso, y precisamente de esto derivaba su argumento en favor del despliegue de antiproyectiles en torno a los emplazamientos existentes. Las restricciones financieras, el temor de desembocar en un sistema estratégico en el que la medida del equilibrio seria mucho más dificil de calibrar que en el sistema actual, el intento de negociación global con los rusos, explican 26tss, Military Balance, : $968-69,0.28$.

${ }^{27}$ R. WeNamara, The Essence of Security, Londres, Hodder and Stoughton, 1968, p. 57. "Nuestra superioridad actual sobre la Unión Soviética en cabezas (nucleares) seguras ("reliable"), precisas ("accurate") y eficaces ("effective") es a la vez mayor de la que habiamos proyectado poseer en un principio y más importante que la que necesitamos".

28 iss, Strategic Survey, ig68, p. 54 . 
ESTUDYOS INTER NACIONALES

sin duda la decisión republicana de continuar la política demócrata que habian denunciado, àsí como también el deseo de favorecer el despliegue del sistema de armas antiproycctiles por toda una serie de complejas razones (Cf. punto c).

b) Los cohetes ugm (Underwater Launched Missile: cohetes lanzados desde un submarino sumergido)

En lo concerniente a los cohetes lanzados por submarinos, los $4^{1}$ sumergibles a propulsión nuclear portadores de cohetes estratégicos ${ }^{29}$ están equipados cada uno con 16 cohetes Polaris ( 13 están dotados de Polaris A-2, que datan de 1963 y tienen un aicance de 1.700 millas y 0,7 megatones); 28 están equipados de Polarts A-3 (que datan de 1964 , consiguiendo un alcance de 2.850 millas, misma potencia explosiva), pero que según una revelación del 6 de agosto están dotados de 3 cabezas de tipo MRV $^{29}$ bis.

El cohete Poseidon, que debe reemplazar a los Polaris, fue probado, al igual que el Minuteman เII, el 16 de agosto de ig68. Todavia no ha sido desplegado. Este cohete, dotado de un MrRv (entre Io y i 6 cabezas nucleares, de un alcance dos veces mayor que los Polaris A-3, o sea aproximadamente 5.000 millas), es aparentemente mantenido en reserva, listo, se dice, para reemplazar a los Polaris a bordo de $3 \mathrm{I}$ de los 4 ! submarinos nucleares, los 10 restantes deben permanecer cquipados con Polaris $\mathrm{A}^{-2^{30}}$. No se conoce el timing de esta opcración de relevo que fuera proyectada por McNamara al mismo tiempo que el programa Minuteman III, en respuesta a los despliegues de ABM soviéticos. ${ }^{31}$

\section{c) Los cohetes ABM}

La Administracion Nixon ha revisado la decisión tomada por la Administración Johnson - con el aval de McNamara- en septiembre de $1967^{32}$,

${ }^{29}$ Existen iguaimente 35 submarinos a propulsión nuclear pero no portadores de cohetes nucleares (ISs, $, 3 B, 1968-69$, p. $5^{2}$ ).

29 bis Declaración de J. Foster ante $4^{x}$ comisión legislativa - 5 de julio - Deciaración del Departamento de Defensa del 5 de julio, El Mercurin, $7 / 8 / 1969$, p. 31.

30 Iss, .uB, $1968-69$, p. 28.

${ }^{31}$ Declaración de .IcNamara del 26 de enero de 1967 (Keesing's Contemporary Archives, $21.915 \mathrm{~A})$.

${ }^{32}$ Ibid. 
Alain Joxe $/$ ¿Fin de la preponderancia estratégica norteamericana?

contraria por lo demás a la opinión del mismo McNamara en enero de ese mismo $a \bar{n} 0^{33}$, de desplegar la red ligera antichina para la protección de ciudades, basadas en los cohetes Spartan y Sprint (Nike X) y cuya instalación entre 1968 y' 1972 debia costar 5.000 millones de dólares ${ }^{34}$. El despliegue de esta red "Sentinel" (cuyo precio luabia aumentado muentras tanto en 2.000 millones de dólares), se justificaba: $1^{\circ}$ porque la capacidad norteamericana de compensar el posible progreso en ABM de los soviéticos mediante despliegues de Mro se mantenia intacta; $2^{\circ}$ porque la puesta a punto por la uRss de los FoBs revelada oportunamente por McNamara en noviembre de $1967^{3 s}$ hacia teóricamente indefendible una estrategia de disuasión norteamericana basada en el desarrollo de los ABr; y $3^{\circ}$ porque la red АвM soviética misma era considerada como ligera 0 limitada: la linca de radares descubierta en Estonia ("Tallin Liné") era considerada una red de alerta antiaérea por el gobierno demócratát ${ }^{36}$, contra la opinión de los militares. En la actualidad, sobrc este puntó, es la opinión de los militares la que se impone $e^{37}$. Por lo tanto, no obstante que

"Discurso en San Francisco de .Mcivamara, 18 de septiembre de 190 7 (Kecring's Con(emporary Archives, 22.325x).

${ }^{34}$ Cf. V'er mi articulo "Cohetes anti-cohetes ¿regreso hacia cstrategias defensivas?", Estudios Internacionales, año $2, N^{\circ} 1$, abril-junio de 1968 , pp. 115-117, y la bibliografia que en el aparece.

${ }^{35}$ Declaración de $\mathrm{A}$ (cNamara del 3 de novicmbre de 1967 , en la que se previa una capacidad operacional inicial de los foss soviçticos en el curso del año a68 (Keesing's Contemporary Archives, 22.359.1). FoBs (Fraclional Orbital Ballistic System "Sistena Balistico Orbital Fraccional) es un término norteamericano. Los soviéticos hablan de "coheles globales", $y$ esto desde hace mucho ticmpo (ig62). Los perfecciunamientos revelados por . WcNamara fueron deducidos de ciertos ensayos suviéticos con satélites de trayectoria muj baja. El Fors no viola e! tratado de no utilización del espacio con fines militares, en la medida en que el objeto no es definido como hallándose en "cl espacio" más que si lleva a cabo una orbita completa, y lo propio del rons es volver a caer sobre la tierra antes de haber concluido dicha revolución. Este tipo de ingenio puede llegar a los Estados Unidos por cualquier asimut. Capaz de burlar la actual red de radares árticos, obligaria a los Estados Unidos a desplegar en todo el derredor de! "santuario" nuevos radares cuyo alcance se extendicra más alla del horizonte, pucsto que la trayectoria de! Fous, mucho más baja que la de los Ices, hace su detección mucho más dificil dentro de plazos convenientes.

${ }^{36} \mathrm{Cf}$. Hanson W. Baldwin en The . Vew York Times, 2 de febrero de 1967 ; Thomas $W$. Wolfe, The Sovict Lnion and the A ват Question (declaracion hecha ante un subcomite para las Aplicaciones Militares de la Comisión de Energin Atómica, L's Congress, 7 de noviembre de $(967)$.

${ }^{37}$ Robert E. HLunter, op. cil., p. :99. 
todo el mundo está de acuerdo sobrc la disminución del ritmo de los trabajos dic instalación Galosh en la Unión Soviéricass, la capacidad antiproyectiles reconocida a la urss aumenta bruscamente. Simultáneamente, como ya hemos visto, el número de los. 1cus soviéticos ha aumentado realmente con rapidez $y$ en consecuencia la vulnerabilidad de los Minuleman.

La versión antichina y defensa de las ciudades del desplicgue Sentinel, hubo de ser reconsiderada asimismo debido a dificultades de indole politica: el Senado, a principios de 1968 , comenzó a reflejar la impopularidad de los despliegues en los suburbios de las ciudades" "protegidas", cuyos habitantes se encontraron repentinamente con que su defensa seria ascgurada mediante una explosión atómica en la atmósfera situada sobre el territorio cubierto (Sprint), amén de las inquietudes de Canadá, cuyo cielo dcbe ser testigo de la explosión defensiva del Sparlan ${ }^{10}$. El Presidente Nixon ha reaccionado frente a esto en dos ocasiones. El 6 de febrero de 1969, decidió la suspensión de los trabajos y' cncargó a D. Packard“, Subsecretario de Defensa, que presentase un informe sobre el asunto a comienzos de marzo. En el curso de febrero, cl Presidente declaró, en términos vagos, que deseaba ver en la red "ligera" un elemento de la defensa global de los Estados Unidos y no solamente un dispositivo antichino. Finalmente, el 44 de marzo, hizo pública su decisión de modificar Sentinel, que pasó a ser el sistcma Safeguard en el argot del Departamento de Defensa. En la red Safeguard, las bases son construidas lejos de las ciudades, su número será de 14 y y'a no de 17 (como en el Sentinel), y el papel principal de los ABM es la protección de los Minuteman.y la protec-

${ }^{38}$ iss, 55 i 968, Pp. $24^{-25}$.

${ }^{39}$ Reacción inversa a aquëlla para la que se preparaban los expertos, los cuales temian mús bien una demanda generalizada de Aas por parte de la población y la presión hacia un sistema pesado, catastrifico parn el presupucsto. A pesar de las apariencias, este segundo riesgo, cn segunda linea, no ha quedado excluido.

${ }^{40} \mathrm{Cr}$. Mensaje (Santiago), $N^{\circ 0}$ I 80 , julio de 1969, pp. 275-240, mi articulo: "Cohetes nucleares, hacia la igualdad y la negociación global".

${ }^{41}$ La elección de Pactiarl como Subsecrictario de Defensa simboliza bastante bien las conexiolses de ia nueva Administración con el mundo de los negocios. Propietario de una empresa especializada en la electrónica (17 Sábricas, 13.000 obreros que producen para ei sector civil y militar). Packard vendió en $: 968$ materiales por valor de 3 t millones dólares al Pentágono, $y$ por valor de for millones a industrias que dependen de éste. Según es costumbre, renunció a sus participaciones financicras durante el ticmpo que desempeñe su cargó. 
Alain Joxe / ¿Fin de la preponderancia estratégica norteamericana? ción de la capital federal, Washington, con exclusión de toda otra ciudad. Para este año no se prevé más que la construcción de dos bases, en Montana y en Dakota del Norte, en torno a dos bases de Minuteman. El proyecto en su conjunto está destinado a proteger a los Estados Unidos contra un ataque accidental, y contra un ataque "del género del que China podría ser capaz de lanzar de aqui a diez años". El interés político inmediato para el Senado, reside en que el proyecto entraña para el año fiscal ig69-1970 una economía de 800 a 1.000 millones de dólares. Pero no se trata de un ahorro real: el conjunto del proyecto Safeguard continúa siendo de 7.000 millones de dólares; como en el intertanto el número de bases previstas se ha visto disminuido de 17 a 14 , se puede hablar incluso de un aumento del precio unitario de la base.

La Administración Nixon modifica los fundamentos racionales de lá decisión, pero mantiene en los mismos términos el nivel de los pedidos colocados a las industrias de armamento. Todo ocurre como si, no habiendo variado la presión en favor de la construcción de ABM, el nuevo equipo se viese obligado a cambiar de sistemas de justificación, aunque sólo sea para demostrar que la Administración precedente era ineficaz. Sigue planteada la cuestión de saber cuáles son las razones estratégicas de la decisión, que fue finalmente aceptada por el Senado norteamericano el 6 de agosto de r 969 con una mayoría de dos votos.

\section{Estrategia norteamericana}

¿Se trata realmente, como lo ha dicho Nixon, de atender rápidamente a un peligro apremiante de protección de los Minuteman, amenazados por el aumento repentino de los ss-9 soviéticos? El peligro provendria a la vez del despliegue de ss-9 y del despliegue de ABM soviéticos. Si los soviéticos se contentasen con desarrollar sus redes de ABM, ello seria tolerable. Lo mismo ocurriria si se contentasen con desarrollar sus MRV. La respuesta norteamericana seria, en el primer caso, el despliegue de los mirv; y en el segundo caso, el de los aвm, alrededor de los silos de Minuteman. El riesgo de desequilibrio importante procede del despliegue (soviético) simultáneo de los ABM y los MIRV ${ }^{42}$.

Los Estados Unidos se verian, en esta hipótesis, doblemente arrastrados

${ }^{42} \mathrm{Cr}$. George Rathjens, The Future of the Strategic Arms Race, Carnegie Endowment for International Peace, New York, 1969, p. 20. 

por las decisiones soviéticas. Bajo Johnson, se lanzó un programa de ABM sobre todo por imitación, a fin de disponer de la misma panoplia o colección de armas que los rusos. Bajo Nixon, se despliegan los ABM para hacer frente a una amenaza concreta de dominio estratégico soviético.

¿Se trata simplemente de una medida de conservación tomada para mantener abiertas las condiciones de una negociación sobre los cohetes estratégiços, antes de la puesta a punto y emplazamiento de los mrrv, cuyo número exacto no puede ser observado mediante satélite, lo cual hace más dificil la medición de las equivalencias? Pero esta forma de ver el asunto, supone que los norteamericanos estaban dispuestos a negociar y que los soviéticos se resistian, siendo lo contrario lo ocurrido en verdad ${ }^{43}$, hasta los últimos pasos dados por los norteamericanos a comienzos del mes de julio de 1969 . El argumento sirve únicamente para cubrir las apariencias en visperas de una negociación que se habia previsto bajo Johnson, pero en condiciones más favorables de equilibrio globàl. Por lo demás, resulta contradictorio defender el proyecto de ABM argumentado, como lo hace M. Laird, un peligro inminente de desequilibrio a favor de los soviéticos y de un proyecto soviético de "victoria" en la carrera, ya que esta justificación puede servir para volver a plantear de nuevo los despliegues de Minuteman III y de los Polaris, más que para disminuir la tensión. Una manera de interpretar la politica de Nixon, tomando en cuenta tales contradicciones, seria pensar que de hecho hoy dia no existe casi relación entre los ABM $y$ la cuestión mucho mảs importante de los MIRv^^. Los soviéticos no han presentado objeción alguna contra el proyecto Safeguard probablemente porque no lo toman muy en serio, como ocurre con un buen número de expertos científicos norteamericanos ${ }^{45}$.

Toda la cuestión, que permanece en suspenso, seria saber si las negociaciones van a versar o no sobre los mirv.

${ }^{43}$ Pasos dados por los soviéticos: - Declaración del Ministerio soviētico de Relaciones Exteriores, 20 de enero de i 969 .

-Articulo de Pravda, febrero de a 969 , sobre la negociación deseada por la urss.

-Entrevista del Embajador soviético en Washington, Dobrynin, con cl Secretario de Estado W. Rogers (8 de marzo de 1969 ).

${ }^{44}$ Hunter, World Today; mayo de ig6g, p. 200.

${ }^{45}$ Las dudas sobre e! cohete Spartan fueron expresadas abiertamente por gran númoro de cientificos, y' especialmente por $J$. Wiesner. 
Conclusión I

Aqui, el observador puede plantear dos hipótesis. La primera hipótesis consiste en postular en el caso del gobierno norteamericano un maquiavelismo particularmente refinado, $y$ suponer que todas las fuentes que señalan el aumento e incluso la superioridad probable de los soviéticos son falsas, y que la alerta al "security gap" está destinada solamente a permitir la prosecución de la carrera de los armamentos indispensable pára el sistema norteamericano. Que se trata, en suma, de una reedición del mito del "missile Gap", lanzado durantè la campaña de Kennedy. Pero no nos hallamos é periodo preelectoral. La rentabilidad politica de la operación es pues escasa o nula. Las declaraciones más alarmistas de la Administración tienen lugar después de las elecciones $y$ no antes. Ningún tipo dé reorganización centralizadora del Pentágono puede en el futuro servir para justificar la revisión optimista de las previsiones catastróficas, como ocurriera después de la asunción de su cargo por McNamara. Las informaciones, además, son hoy dia mucho mảs precisas gracias a los satélites espias. La hipótesis del "inflamiento" o exageración sistemática de los progresos soviéticos significaria entonces que el "complejo militar-industrial" denunciado en su día por Eisenhower, no necesita siquiera aprovecharse de las campañas electorales para volver a iniciar la carrera de los armamentos, y no es ya permisible acusar a los militares de incuria y desvario.

La segunda hipótesis es considerar que, en general, las fuentes norteamericanas son honestas, y. que el gobierno no actúa bajo la presión del "complejo militar-industrial" (excepto tal vez en lo referente al "pequeño" pedido de ABM), sino más bien bajo la presión soviética. Las contradicciones y la incomodidad evidentes de los republicanos se derivaría de que, por primera vez quizás en la historia de la confrontación Este-Oeste, los Estados Unidos no pueden, aunque quisieran, negociar a partir de una posición de fuerza.

En la primera hipótesis, veriamos a los Estados Unidos, como nación, dirigidos por un grupo que, objetivamente, le hace el juego a la URss, ya que tiene interés en "inllar" el poderio soviético en sus menores manifestaciones (el año pasado, la alerta de los A BM; este año, la alerta de los ss-9; pronto, la alerta de los cohetes submarinos). Se puede hablar de preponderancia soviética debido a que son los soviéticos los que dirigen este juego 
E S T U D I O S I N T ER N A C I O N A L E S

mediante "el lanzamiento" de un producto, y a que el sistema norteamericano está obligado a seguir por la lógica interna del sistema que le dirige.

En la segunda hipótesis, los soviéticos dominan cuantitativamente, y por consiguiente son directamente preponderantes.

En ambos casos, el fin de la preponderancia estratégica norteamericana queda pues establecido, ya sea al nivel de los medios políticos de influencia $o$ al nivel de los medios militares.

Esta situación es en parte el resultado de un proyecto "kennediano", y en parte el resultado de una maniobra de desbordamiento soviética llevada a cabo estruendosamente, aprovechándose del periodo del interregno.

II. LOS DESPLIEgUeS DE LOS MEDIOS DE INTERVENGION LOCAL A ESCALA MUNDIAL

Para la Unión Soviética, más que para toda otra potencia politica, la acción militar, politica y económica forma un todo unificado por una estrategia total, al menos en teoria. Pero el radio de acción de esta estrategia total de la uriss se limitaba hasta estos últimos años a Europa y las zonas adyacentes. Lo nuevo es que, por primera vez desde el comienzo de su historia, la Unión Soviética se dispone a darse los medios necesarios para una penetración militar y económica mundial. Estos medios están en vías de igualar o de superar a los medios norteamericanos en un cierto número de dominios. Se trata en este caso de la consecuencia de un plan estratégico definido y claramente expuesto que señala por parte de la Unión Soviética una reivindicación muy firme de igualdad en todo el mundo con los Estados Unidos.

\section{La igualdad reivindicada}

Esta doctrina de igualdad es relativamente reciente. Hace seis años, en julio de 1963 , el almirante Gorshkov, Comandante en Jefe de la flota soviética, habia anunciado el papel estratégico autónomo y ofensivo que debia desempeñar en el futuro la flotà soviética:

"En el pasado, escribia, nuestros navios y nuestra aviación naval operaron principalmente cerca de nuestras costas.. ocupándose ante todo de la coordinación táctica $y$ de 
Alain Joxe / ¿Fin de la preponderancia estratégica norteamericana?

operaciones realizadas conjuntamente con las fuerzas terrestres. Ahora, debemos estar preparados, por medio de grandes operaciones ofensivas, a asestar golpes demoledores contra los objetivos de los imperinlistas, situados en el mar o en tierra, en todos los puntos de los ocianos del mundo entero y los territorios adjacentes" "A.

Hace dos años y medio, en febrero de 1967 , el almirante Gorshkov publicó un articulo titulado Desarrollo del arte soviético de la conducción de la Guerra Vaval. En esc articulo, el Comandantc en Jefe declaraba entre otras cosas:

"En el modo y medida us que aumenta el poder económico de la uRss, sus intereses en los mares $y$ ocisulos van igualmente aumentando siemprc más $y$ csto corresponde a nucvas tarcas que se inponen a las fuerzas navales con vistas a la defensa (de estos interescs) contra las empresas de los imperialistas"

En ese mismo artículo, el almirante soviético proclamaba igualmente la irreversible decadencia del portaviones clásico como principal tipo de unidad de ataque del poderío naval moderno"s, y celebraba el advenimiento del submarino de ataque, portador de cohetes nucleares o no, por constituir la nueva arma esencial del dominio de los mares; dicho de otro modo, Gorshkov fundamentaba la superioridad de la Unión Soviética en la justeza de sus elecciones estratégicas $y$ no solamente en la cantidad de armas, ya que, como es sabido, la Unión Soviética no posée un solo portaviones.

A comienzos de i 968 , el almirante Gorshkov, nuevamente, declaraba:

"La l'rss habia pucsto a punto la creación de una marina moderna, enteramente de alta nar, que respondc plenamente a las exigencias de la guerra de cohetes nucleares"... "que ella poscin alıora navios equipados en muy alto grado de medios de navegación automática capaces de navegar en alta mar indefinidamente, de asestar golpes porlerosos contra un enemigo $y$ de proteger nuestras instalaciones de los ataques por mar.

${ }^{45}$ Gorshkov, S. Comunist of the Armed Forces, julio de 1963 , citado por Edmonds y' Skitt, op. cil. International Iffairs, vol. $45, \mathrm{~N}^{\circ} 1$, cnero de $196 \mathrm{~g}, \mathrm{p} . \mathrm{t}^{2}$.

Un primer indicio de esta revolución en la doctrina naval estratégica, es igualmente perceplibic en la segunda coición de La Estrategia Militar de Sokolovski, publicada en 1963.

47 Serguei Gorshkov, "Razvitiye sovietskogo voyenno morskngo iskustya", Morskoj" Stornik, $\mathbb{N}^{\circ} 2,1967$. p. 21. Citado por Lincoln Landis, "Der Suezconal in der politischen Strategic der Sovielunion", Europa Arehiv, No 3,1969 , pp. :09-110.

${ }^{46}$ Gorshkov, Ibid., pp. 18-19, citalo por Thomas Wolfe, Evolution of Soviet Military Power, Rand Paper, P. 3773. p. 23. 


\section{ESTUDIOS INTER NACIONALES}

Todo csto", decia "ha puesto a nuestra marina a! rivel de las fuerzas que pueden realizar misiones estratégicas de naturaleza ofensiva"

Por último, ẹn un discurso pronunciado el $27 \mathrm{dc}$ junio de 1968 ante el Soviet Supremo, el Ministro Soviético de Asuntos Exteriores, Andrei Gromyko, estableció en cstos términos los principios y los fines de esta nueva capacidad naval en el plano de la estrategia politica global de la Unión Soviética:

\footnotetext{
"La igualdad de dercchos en todos los sectores $y$ en todas las esferas de actividades en ta arena internacional, comprendida la adopción de medidas para proteger los intercses vitales de la Unión Sovićtica, de sus aliados $y$ de sus anigos; nada de discriminación en cl comercin mundial; intercanbios intensivos de valores cientificos, tecnolögicus y culturales; libcripd de navegación para nucstros navios ; flotas de cualquier otra potencia que sea, indo esto determinn nucstras posibilidades $y$ nuestras responsabilidades en el mundo"so.
}

\section{Cuba 7962}

Al recordar, como lo hemos hecho, las etapas de la proclamación de la doctrina, debe recordarse que una reivindicación de igualdad habia sido ya presentada muy formalmente por Jruschov en 5962 , en visperas de la crisis cubana, en la nota de la Agencia TASs del 1 de septiembre: "Derechos iguales y posibilidades iguales deben ser reconocidos a todos los paises del mundo... Los Estados Unidos se movilizan, por asi decirlo, porque nuestros barcos mercantes se dirigen hacia Cuba, pero navios de guerra, toda la Scxta Flota, se encuentra en el Mediterrâneo. ¿A cuántos kilómetros se cncuentra éste de los Estados Unidos?... y sin embargo, se dice que los Estados Unidos tienen derecho a estar alli... lo que es declarado "violación de las normas" para uno, es considerado normal para otros. Advertimos que, dadas las condiciones presentcs, el campo socialista no tiene menos fuerza y posibilidades que los Estados Unidos y sus âliados"s"

La base económica y organizativa de esta reivindicación era chtonces sólo un proyecto. Asi Jruschov inspirado en la visión grandiosa del desarro-

${ }^{49}$ Cilado por Rolsert A. Kilmarx, "Introducción", csts, ssp, p. 1: .

so Sovict leuss (publicación del Departamento de Prensa de la Embajada soviètica en Londres) 2 de julio de 1968 , pi 11.

${ }^{1}$ Larson, Cuban Crisis of 1002, documento 5, p. 13. 
Alain Joxe / $i$ Fin de la preponderancia estratégica norteamericana?

llo por la planificación del poderio económico socialista, en el mismo mes de septiembre de 1962 decia: "Hoy estamos confrontados a la necesidad de ir más lejos, y partiendo de la planificación al nivel nacional progresar hacia la planificación al nivel del Came (Comecos) y luego llegar al nivel del sistema socialista mundial considerado como un todo. Nuestro objetivo es construir la economia mundial como una entidad única".

La diferencia entre la Unión Soviética de 1962 y la Unión Soviética de :969, consiste en que Jruschov, demasiado confiado en la influencia de los cohetes estratégicos, debió "balandronar" para defender a Cuba contra lo que pensó ser un peligro de ataque norteamericano, en tanto que el equipo Brezhnev-Kosygin se halla hoy dia efectivamente dotado de un potencial nuevo e impresionante, de presencia y de acción naval, que les permitiria sin duda actuar muy distintamente en coyunturas locales particulares comparables a las de Cuba en 1962.

La nueva orientación naval de la Unión Soviética aparece asi claramente como la consecuencia de las enseñanzas de la crisis cubana de $9662.52^{-}$ Pero es también y más simplemente el aspecto naval del crecimiento global del poderío soviético desde el punto de vista económico, tecnológico $y$ cientifico ${ }^{53}$ cuyas consecuencias hemos visto revelarse en el dominio de los cohetes.

Para apreciar la importancia estratégica del esfuerzo soviético se pasarát revista a los siguientes puntos:

I. Se estudiarán los medios de la nueva presencia naval soviética mundial; en primer lugar, se tratará rápidamente del crecimiento de las flotas mercante y pesquera, que constituyen, en tiempos de paz, el aspecto de esos "intereses" en expansión de la Unión Soviética que se trata de defender, según Gorshkov, contra las empresas occidentales; a continuación, se describirá el mejoramiento cuantitativo y cualitativo de la flota de guerra soviética. Finalmente, se dará una idea del agrandamiento constante de las zonas de frecuentación habitual de las flotas soviéticas, deteniéndose un poco más en los casos típicos de la penetración en el Mediterráneo y el avance hacia el Océano Indico.

$=2 \mathrm{C}$. Wolfe, The Soviet Quest..., RAxD memorändum RM $5554 \mathrm{PR}$, diciembre de $99^{67}, \mathrm{p}$. 15; Com. Robert B. Rogers, "Trend in Soviet Naval Strategy", Naval H'ar College Review, febrero de ig69. "En el curso de la crisis cubana, en la humillación, los soviéticos aprendieron el verdadero signiticado del poderío naval".

${ }^{53} \mathrm{Cf}$. Thomas Wolle, en csis, ssP, p. 117. 
E S T U D I O S I N T E R N A G I O N A L E S

2. En una segunda parte, estratégica, se compararán los dos potenciales, norteamericanos y soviéticos, y se intentará definir qué estrategias políticas y militares van implicitas en la confrontación actual.

\section{La flota mercante}

A partir de 1950 , la flota mercante soviética se ha incrementado en forma considerable, y continúa creciendo a un ritmo muy superior al de la flota norteamericana ${ }^{54}$. Este crecimiento es evocado en el cuadro $N^{0}$, el que a falta de estadísticas más coherentes, da no obstante una idea de este progreso: .

\section{Cuadro I}

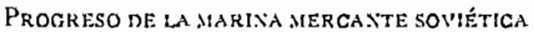

\begin{tabular}{|c|c|c|c|c|c|}
\hline & A.No & TONELAJE & $\begin{array}{l}\text { NUMERO UE } \\
\text { UXIDADES }\end{array}$ & ORSERVACIOYES & FUENTE \\
\hline & 1950 & 1.800 .000 & 432 & (navios importantes tan solo) & (a) \\
\hline & 1958 & 3.600 .000 & ? & ? & (c) \\
\hline 30 de julio & 1963 & 5.433 .765 & 1432 & (sin los auxiliarcs) & (c) \\
\hline $1^{\circ}$ de enero & 1964 & 6.600 .000 & 2655 & (comprendidos los auxiliares) & (c) \\
\hline $1^{\circ}$ de enero & 1965 & 7.149 .273 & 2838 & (comprendidos los auxiliares) & (d) \\
\hline estimación & 1969 & 12.000 .000 & 1442 & (navios importantes tan solo) & (a) \\
\hline $\begin{array}{c}\text { para } \\
\text { estimación }\end{array}$ & 1970 & $=14.800 .000$ & 2600 & (navios importantes tan solo) & (a) \\
\hline para & 1980 & 27.200 .000 & 4300 & (narios importantes tan solo) & (b) \\
\hline
\end{tabular}

FUE.TTES:

(a) csts, SSP, p. 5.

(b) cris, s5P, p. 81.

(c) A. Boy'er, "Les artivités maritimes de l"Union Sovietique". Notes el Etudes Doeumentaires, NN 3415, 1/9\%1967, p. 22.

(d) Revue maritime, agosto-septiembrc, 1965.

${ }^{54}$ Barcos mercantes en los astilleros para el cómputo de la unss y de los Estados Unidos, entre 1962 y $: 967$ :

$\begin{array}{lccc} & & \text { L'Rss } & \text { EE.UU. } \\ \text { Marzo } & 1962 & 225 & 61 \\ \text { Mayo } & 1963 & 236 & 47 \\ \text { Mayo } & 1964 & 441 & 47 \\ \text { Octubre } & 1965 & 464 & 39 \\ \text { Noviembrc } & 1966 & 556 & 48 \\ \text { Diciembre } & 1967 & 37^{6} & 6 ! . \\ \text { Fueste: csis, ssp, p. \&4. } & & & \end{array}$


Alain Joxe / ¿Fin de la preponderancia estratégica norteamericana?

El número total de los navios soviéticos supera hoy dia al número total de navios mercantes norteamericanos, incluso si el tonelaje soviético es todavía ligeramente inferior al tonelaje norteamericano. Esta flota es en su conjunto mucho más reciente y más moderna que la flota mercante norteamericana ${ }^{551}$. Es justo señalar que la comparación desde el punto de vista del potencial comercial debería efectuarse más bien entre la totalidad de las flotas occidentales $y$ el conjunto de las flotas socialistas, en cuyo caso la superioridad cuantitativa de occidente sigue siendo notoria $^{56}$. Pero las flotas mercantes de los btros paises socialistas, miembros del Pacto de Varsovia ${ }^{57}$ y Cuba ${ }^{58}$ se encuentran igualmente en pleno desarrollo. Además, desce el punto de vista del poder de negociación y del peso que puede representar la existencia de la capacidad soviética. de transporte maritimo en las negociaciones internacionales sobre fletes, el instrumento, centralizado en las manos del Estado, que representa la marina mercante soviética, puede ya imponer sus condiciones sobre puntos precisos.

\section{La flota pesquera}

La flota pesquera soviética es la más importante del mundo ( 17 veces más importante que la de los Estados Unidos), y una de la más modernas. Está organizada para la exploración y explotación cientifica de los fondos marinos, y dispone de una flota de navios oceanográficos que es igualmente la más importante del mundo ${ }^{59}$.

Esta flota se ha ido alejando cada vez más de sus bases en el curso de los 9 últimos años, como se ve en el cuadro siguiente (cuadro II).

5s Según csis, sse, p. 5 ; No $34 ! 5$, p. 23 , indica que ya en 1966 , el $77,5 \%$ de las unidades tenia menos de ra años de edad, y que el $75,7 \%$ de los navios mercantes estaba dotado de propulsión a motor, y el $3,6 \%$ de turbinas a gas. Mientras que en 1958 , el $5,9 \%$ solamente de las unidades navegaba a más de 44 nudos, en i $966 \mathrm{el} 66 \%$ alcanzaba esta velocidad.

${ }^{56} \mathrm{La}$ flota mercante soviética no podia todavia en $: 967$ asegurar más del $50 \%$ del tráfico requerido por sus intercambios extersores, según $N^{\circ} 3415,1^{\circ}$ de septiembre $d c: 967, p .4^{2}$.

${ }^{57} \mathrm{Csis}, \mathrm{SSP}$, p. 89.

${ }^{58}$ Cf. Hans Felsen, "Kubas Flotte", Horizonl (Berlin-Este), $N^{\circ}$ 20, 1969, p. 22. La flota cubana pasó de 93.378 t. de tonelaje bruro en 1962 , a 335.765 t. de tonelaje bruto en 1968 .

${ }^{59}$ ND $3415 ;$ p. 34. 
Cuadro II

EXPaNisióN de LAS fLOTAS de PESCa SOVIËTICAS

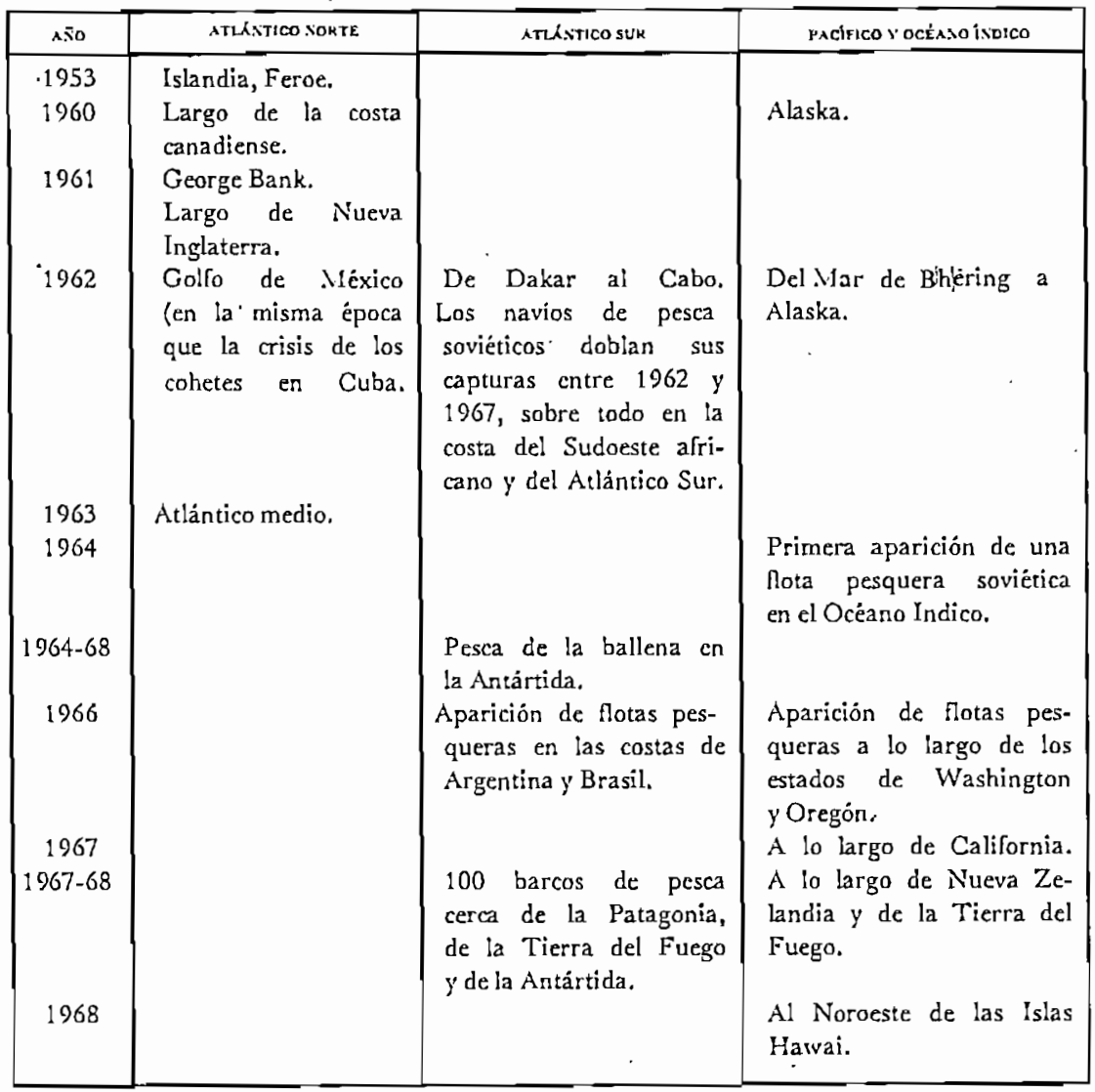

No se debe al azar que ella preceda por doquier a la flota de guerra soviética. Se encarga, en efecto, no sólo de llevar a buen fin las campañas de pesca, sino también de realizar un trabajo de exploración indispensable en particular para là navegación submarina. Además, es preciso hacer constar que el esfuerzo de renovación fue reconcentrado igualmente poco después de la crisis de ig62. En i 964 , a consecuencia de este pedido masivo, entraron en servicio 120 unidades, entre las que se contaban 21 traineras frigorificas, procedentes tanto de los astilleros rusos, polacos y alemanes orientales, como de los paises occidentales. La coordinación entre los planes de expansión de las tres marinas, aparecerá aun con mayor claridad si estudiamos ahora la flota de guerra. 
Alain Joxe / ¿Fin de la preponderancia estratégica norteamericana?

La flota de guerra: sintesis histórica

El $99 \%$ de las unidades de la flota soviética fue construido después de 1949 y la mayoria de ellas después de 1960 ; mientras que sólo el $42 \%$ de las unidades de la flota norteamericana es posterior a $1949^{60}$.

Stalin habia comprendido la importancia de una nota soviética poderosa, tanto para el apoyo ofensivo a las revoluciones (a causa de la experiencia desdichada de la Guerra de España), como para la defensa costera de lă Unión Soviética. Lanzó sucesivamente varios programas de construcción, espccialmente en $194 \mathrm{I}$, en visperas del ataque alemán, y en 1946. Pero habia menospreciado èl papel de los portaviones en su programa de guerrat y' se mantuvo demasiado apegado a la artilleria convencional en su programa de posguerra. A su muerte (1953), la flota soviética era todavia muy clásica, pero en pleno desarrollo a partir de 1950. Las bases del desarrollo ulterior estaban ya echadas, especialmente en el plano de la formación del personal de navegación. El portaviones scguia estando excluido, ya que hạbria sido demasiado costoso intentar competir con Occidente en este dominio, y las tarcas asignadas a la flota seguian siendo esencialmente defensivas.

El mariscal Zhukov, Ministro de Defensa, lanzó en 1965 un programa de modernización, y entre 1957 y $195^{\circ}$ puede situarse el inicio de una reconstrucción radical de la marina de gucra soviéticalo2. La doctrina que presidia la gestación de los programas de construcción habia variado. Asi es como, Jruschov, fascinado personalmente por la importancia de los cohetes nucleares y que debió luchar en aquella época contra la resistencia de los técnicos tradicionalistas del Ejército, asignó a la marina tarcas relacionadas con la disuasión nucicar, $y$ puso el acento únicamente en los submarinos portadores de cohetes, llegando incluso a burlarse de los navios de superficic. La Doctrina Jruschov se impuso oficialmente en 1960-6:, pero los expertos sovićticos, y en especial el almirante Gorshkov, parecen no haber aceptado jamás la totalidad de sus concepciones. A la vez que admitiendo la parte de los puntos de vistá jruschovianos que ponian el acento en la importancia de la lota submarina, di-

${ }^{60} \mathrm{csis}, \mathrm{sSP}, \mathrm{p} .3^{6}$.

"Almirante $\lambda^{\prime}$. G. Kuznetsov, "Recuerdos: antes de la Guerra", International Affairs, $N^{\circ} 12$, diciembre, p. 95 .

${ }^{62}$ Lidmonds y Skills, $\omega$, enero, 1969, p. 29; Raoust, RDs, abril, :969, p. 63.4. 
chos expertos lograron probablemente convencer a Jruschov de la necesidad de conservar una flota de superficie, aunque no fuese más que para facilitar la protección del potencial submarino, $y$ adoptaron medidas conservadoras, optando francamente por la calidad a expensas de la cantidad, en el contexto de una asignación presupuestaria limitada.

Después del asunto de Cuba, entre 1962 y 1964 , se vuelve a emprender pues el esfuerzo hacia la flota de superficie, sobre la base de prototipos ultramodernos $y$ sacando el máximo beneficio de la demora más o menos forzosa, pero que tuvo la ventaja de permitir a la marina servirse de todos los progresos registrados en el dominio de los cohetes y de la electrónica.

El producto actual de estos cambios de dirección, es un conjunto diversificado de unidades extremadamente modernas y bien equipadas, armadas en una proporción mucho mayor que en el caso de la marina norteamericana, de cohetes nucleares o clásicos de todos los alcances y usos, y que va a permitir a la Unión Soviética desempeñar a su manera un papel en la "diplomacia de las cañoneras" que se inició con la parálisis nuclear.

\section{La flola de superficie}

Con respecto a la flota de superficie, se notará en el cuadro iri la ausencia total de portaviones y la presencia de algunas unidades de un tipo muy novedoso. Por ejemplö, los dos portahelicópteros del Mar Negro, el Woskva (1967) y el Leningrad (1968), de 19.000 toneladas de desplazamiento, concebidos y armados especialmente para la caza antisubmarina, y dotado cada uno de ellos de 20 o $3^{6}$ helicópteros ${ }^{65}$. Para apreciar la potencia de los grandes navios de superficie, es preciso señalar la existencia hoy dia de 5 (o más) cruceros del tipo Kresta, aparecidos en 1967 , equipados con cohetes superficie-aire, superficie-superficic $y$ de armas antisubmarinas, $y$ cuya propulsión está asegurada por un motor de turbina a gas. Este tipo de buque no tiene equivalente en ninguna marina del mundo64

${ }^{63} 20$, segín csis, SSP, 37; 36, según Peter Kruzhin, "The Soviet Flect in the Kediterranean", Bulletin (Institute lor the Study of the urss, ..Lunich), vol. Xv1, $N^{\circ} 2$, febrero de $19^{6} 9$, p. 38 .

${ }^{64}$ La propulsión por turbina a gas fue introducida en 175 barcos sovicticos, civiles $y$ militares; no existe más que en un solo barco norteamericano, según csis, SSP, $3^{8}$. 
Alain Joxe / ¿Fin de la preponderancia estratégica norteamericana?’

\section{Cuadro III}

\section{DISTR:BUCIÓN DE LAS UNIDADES SOVIÉTICAS}

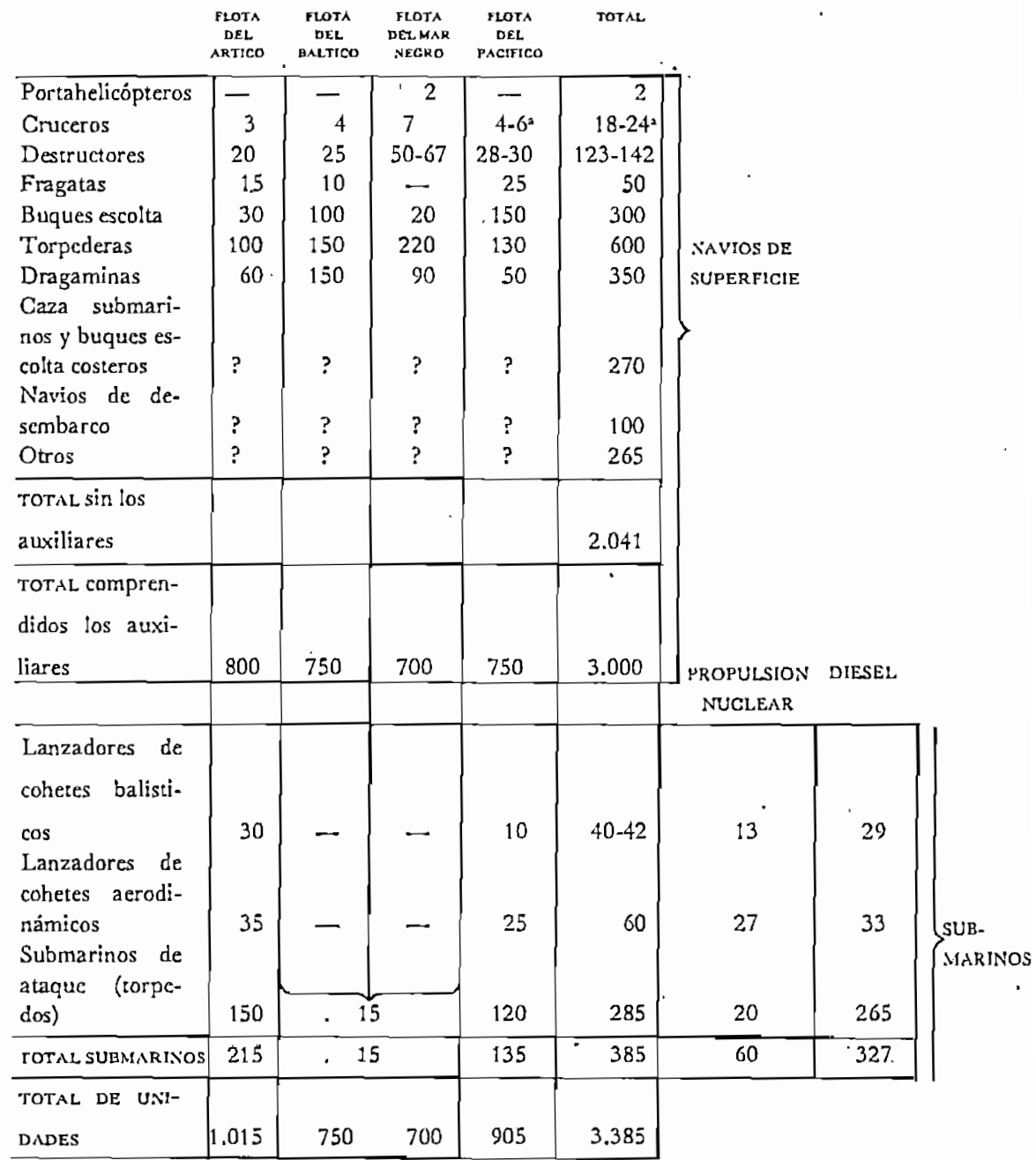

(a) 4 cruceros en el Pacifico según 1s; 4-6, scgún ssp.

(b) 50 "destructores $y$ buques de escolta" en el Mar Negro según Ja; 67 destructores según ssp.

(c) 28 destructores en el Pacifico, según 1a; 30 según ssp.

(d) Existirían 163 "destructores clásicos", según RDN.

(c) Los submaririos, scgín 1ss, Military Balance 1968-59, estarian repartidos de la siguiente manera: Artioo, 40; Báltico, 70; Mar Negro, 40; Pacifico, 100, Total: 380.

r testes: Este Radro gencral se ha establecido subre ta base de cifras proporcionadas por csis, Soviel Sea Power (ssp), gtá-

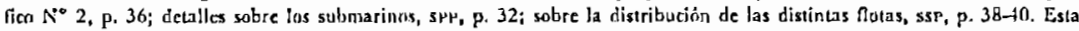
ivente, que es la la más reciente, rectifica las fuentes anteriores: Nilitary Ralance, 19608-69, pp. 7.8 Y p. 52; RAOusT.

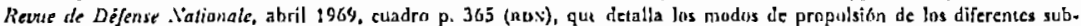
marinos: tososs y skitrs, Intemational Affarr (Londres), enero de $996 \%$, cuadra p. 30 (L), que detalia ta distribución de 
Las flolas, pero depende a su vez de Miliany Babnce, 1967-68, Time Magazine, 23/2/1968 y de aralosen, usiv, Mslitule Procededings, junio de 1967, p. 56 sobre ia floca ática, y diversas otras fuentes que datan de 967 y ya superadas. En conjunto, todas otas fuentes resultan compatibles con la excepción de algunas unidades, teniendo en cuenta las tasas de progreso generalmente admitidas, a pesar de incertidumbres muy explicables sobre la distriburión de los submarinos, su número exacto y su modo de propulsión y armamento. Existen también incoherencias debido a que las dimensidnes de los navios sovieticos ho calzan exactamente con las dimensiones o los tonelajericorréspondientes a las denominaciones ocridentales. Asi, tencmas que ciertos autores consideran a deteminadas fragatas como cruceros ligeros, determinados destructores comio fragatas, determinados buques de escolta como destryetores, etc.

Otro rasgo caracteristico de la flota soviêtica es la abundancia de pequeños buques de superficie, lanchas y patrulleras ultrarrápidas, algunas de las cuales están muy armadas y que representan, bajo una forma reduci$\mathrm{da}$, una potencia de fuego tal que se les ha podido llamar "igualizadoras",os en confrontaciones navales locales aparentemente desiguales. Tal es el caso de $5^{0}$ patrulleras de la clase Komar y de las 100 patrulleras de la clase Osa, que constituyen armas temibles. Las $\operatorname{Komar}$ ( $75 \mathrm{t}$.) poseen dos rampas de lanzamiento de ingenios superficie-superficie de corto alcance. Las Osa, entradas en servicio en 1954, son más importantes ( 150 t.) y están armadas de 4 rampas de lanzamiento de cohetes "superficie-superficie", cuyo alcance seria de aproximadamente 10 a 15 millas náuticas ${ }^{66}$.

\section{Los submarinos}

En lo concerniente a los submarinos, el cuadro toma en cuenta dos tipos posibles de clasificación: según la propulsión (nuclear o diesel) y' según el tipo de armamento (proyectiles balísticos, proyectiles aerodinámicos, torpedos). El potencial "armas nucleares" de los submarinos soviéticos sigue siendo una incógnita, ya que los proyectiles balísticos, los proyectiles aerodinámicos y los torpedos pueden indistintamente estar dotados de cabezas nucleares o clásicas. En todas las hipótesis, el arma submarina representa una temible fuerza de ataque a distancia - ya sea contra los territorios enemigos, contra las concentraciones navales adversarias; - cóntra los convoyes-, que cumple muy bien el papel de equivalente estratégico del portaviones, al menos en la hipótesis de una guerra general: los soviéticos han preferido reemplazar el dominio del aire por el dominio de los fondos submarinos. Se supone que, hasta el presente, sus técnicas de detección submarina no son lo suficientemente buenas como para asegurarles ese dominio de las profundidades al que el número de sus submarinos les daria acceso. Pero estas lagunas están en vias de ser

${ }^{65} \mathrm{~L}$. W. Martin, The Sea in Modern Strategy, Londres, iss, : 967 , p. :22.

66 :D 3415, p. I7. 
A lain Joxe / ¿Fin de la preponderancia estratégica norteamericana?

superadas, y los recientes progresos de los soviéticos no se hallan.lejos de anular la relativa invulnerabilidad de los submarinos Polaris norteamericanos ${ }^{67}$.

No obstante, mientras las operaciones concretas a realizar sean más bien del orden del "golpe de amonestación" (ataque preventivo), incluso de la maniobra de intimidación, que del de la guerra generalizada, la unidad de superficie sigue siendo la más significaliva, y por consiguiente se plantea la cuestión del apoyo aéreo.

\section{La aviación naval}

La aviación naval soviética existe pues, $y$ tiene sus bases únicamente en tierra (a excepción de los helicópteros de los dos portahelicópteros y de los. helicópteros con que van equipâdas ciertos tipos de fragatas) or .

La protección antisubmarina del tráfico costero está asegurada por hịdroaviones. Para la alta mar, la lucha antisubmarina deberá correr a cargo de un nuevo avión patrullero poderosamente armado y dotado de una autonomia muy grande. Por el momento, esta tarea, asi: como el. bombardeo, está confiada a los aparatos de radio de acción medio y largo en uso en la aviación, comprendidos ciertos modelos ya antiguos ${ }^{60}$, con las limitaciones $y$ là rigidez que este género de máquinas implicaria de surgir la necesidad de apoyar operaciones delicadas de tipo demostrativo más que destructivo. Pero la necesidad de portaviones no se ha hecho sen-

${ }^{57} \mathrm{CStS}$, SSP, $4^{1}$.

${ }^{68}$ Las 8 tragatas de la clase Kroupnyi entradas en servicio a partir de s960 (4.500 i. 35 nudos, dos rampas de ingenios superficie-superficie, "stock" de 44 proyectiles balísticos, 16 piezas de 57 antiaéreas, dos lanzacohetes ASM) incorporan una zona de aterrizaje para un helicóptero (No 3415, p. 17 ).

${ }^{6} \mathrm{He}$ aqui el nümero y el tipo de aviones de la aviación naval soviética:

$\begin{array}{cccccc}\text { Número } & \text { Tipo } & \text { Radiode acción } & \text { Mach } & \begin{array}{l}\text { Autonomia } \\ \text { de vuelo }\end{array} & \begin{array}{l}\text { entrada } \\ \text { en servicio }\end{array} \\ 300 & \text { TU-16 Badger } & 1350 \text { náuticas } & 0,87 & 3000 \text { millas } & 1955 \\ ? & \text { TU-22 Blinder } & \text { iooo náuticas } & 1,9 & 2000 \text { millas } & 1962 \\ 5^{0} & \text { TU-20 Bear } & 4500 \text { náuticas } & 0,78 & 7800 \text { millas } & 1956 \\ ? & \text { M-4 Bison } & 3000 \text { kilómetros } & 0,87 \cdot 6050 & 1956 \\ 50 & 11-28 \text { Beagle } & 1800 \text { kilómetros } & 750 \mathrm{~km} / \mathrm{h} & \end{array}$

(Iss, мB : g68-69, pp. 8 y 54; No 34!5, p. 18-19). 
que en un punto dado del globo, la urss es actualmente capaz de amenazar con una intervención limitada, $y$ esta capacidad modifica por sí misma la libertad de acción de los Estados Unidos en términos politicos de dificil ponderación. El efecto de disuasión no es jamás, tanto en materia de desembarco anfibio como en materia de potencial nuclear, exactamente proporcional a la capacidad militar efectiva.

Puede decirse que las debilidades relativas de la uRss están en vias de ser enjugadas:

- en el dominio de la lucha antisubmarina;

- en el dominio del adiestramiento en operaciones anfibias.

La superioridad de los Estados Unidos en materia de portaviones puede ser probablemente anujada por el dominio del espacio submarino por los soviéticos, pero se comprende bien que este equilibrio estratégico no concierne más que a la hipótesis de la guerra total, puesto que los soviéticos no podrán entonces obtener la libertad de acción que les proporcionaría la anulación de la superioridad en cuanto a apoyo aéreo de los Estados Unidos más que hundiendo los portaviones norteamericanos. Por debajo de este nivel de crisis, es decir en los casos de confrontación más probables, la superioridad de los norteamericanos, gracias a su (fuerza) aeronaval, prevalece. Toda la cuestión de la potencia real de las fuerzas soviéticas en la aplicación cotidiana a las luchas de influencia local, gira pues en torno a esta cuestión del apoyo aéreo, pero nos vemos obligados entonces a descender del nivel de las hipótesis globales, para tratar casos concretos, es decir, tipos concretos de equilibrios regionales que la marina soviética se dispone a crear al manifestar su presencia por doquier.

\section{La expansión de la flola soviética}

Como se constata en el cuadrolí, la marina de guerra soviética está repartida normalmente en 4 flotas distintas, de las cuales las más importantes son la Flota del Artico y la Flota del Pacifico, no solamente a causa del número total de unidades de superficie que tienen asignadas, sino también porque son las únicas dos que cuentan con submarinos lanzadores de cohetes. El Mar Negro y el Mar Báltico no se prestan al estacionamiento de unidades estratégicas de esta importancia, que correrian el riesgo de verse bloqueadas en caso de crisis "nuclear".

Empero, esta distribución nominal no da la imagen exacta de la forma 
Alain Joxe / ¿Fin de la preponderancia estralégica norteamericaná?

en que la marina ocupa los mares. Importantes desplazamientos tienen lugar de un mar a otro, $y$ desde hace varios años se efectúan regularmente cruceros lejanos por zonas cada yez más apartadas. Insensiblemente estos cruceros se transforman, mediante permanencias prolongadas en fondeaderos de aita mar, en la constitución de destacamentos permanentes. Puede hablarse de la constitución defacto, desde 1967 por lo menos, de una auténtica flota permanente del Mediterráneo. El mismo fenómeno se prepara tal vez en el Océano Indico.

\section{La aclividad de las flotas del Vorle y del Pacifico}

La actividad a larga distancia de la flota sovictica se manifestó por primera vez con ocasión de la crisis de ig62. Cierto número de submarinos habian sido observados entonces no lejos de la zona de intercepción señalada por la "cuarentena", y algunos fueron incluso rastreados y obligados a salir a superficie. Pero ningún barco de superficie se aventuró entonces por el Caribe.

En 1966, se dio gran publicidad a un viaje de circunnavegación de submarinos a propulsión nuclear ${ }^{77}$. Por otra parte, la ayuda al Vietnam constituye un ejercicio permanente de navegación por el Pacifico, y una experiencia nueva desde el punto de vista naval. Por lo general, las unidades de guerra no se aventuran cerca de Vietnam, pero la flota del Pacifico lleva a cabo frecuentemente actividades en el mar de Bhering, los mares del Japón, de la China y de las Filipinas. En 1967 , dicha flota se infiltró, contra todas las prácticas tradicionales, al interior de formaciones norteamericano-japonesas en plenas maniobras de entrenamiento en la guerra antisubmarina. En febrero de 1968 , una flota soviética se interpuso muy rápidamente entre Corea del Norte y la flotilla norteamericana que habia sido enviada para apoyar las exigencias de los Eslados Unidos concernientes a la tripulación del barco espia Pueblo, capturado por los norcoreanos. Esta maniobra pesó en la adopción de una actitud muy moderada por Washington en todo el asunto. Además, la urss intentó en el plano politico, aunque sin éxito hacer admitir para el Mar de Okhotsk y el Mar del Japón el principio a doptado por el estatuto de mar cerrado

77. Michael Gciter, "Soviet Missiles Subs Patrol Ofr ts", Misiles and Ruchets, 4 de abril de :gób, p. 12; Discurso de .Malinovski en el 23 Congreso del Pcus, Krasnaia Zuezda, a de abril de 966 ; Wolfe, x.s 5554, p. g. 
E S T U D I O S I N T E R N A G I O N A L E S del Mar Negro (limitaciones a los navios de guerra de los países no ribereños) ${ }^{7 R}$. Finalmente, las maniobras conjuntas con las fuerzas del Pacto de Varsovia en el Atlántico han tomado recientemente una importancia cada vez mayor. Asi por ejemplo, la operación Sever (Aorte) del verano de 1968, cubrió el Atlántico Norte, el Báltico, cl Mar de Noruega, el Mar del Norte y el .har de Barents con una serie de ejercicios muy variados, comprendidas maniobras de desembarco anfibio con participación de contingentes polacos y alemanes orientales ${ }^{79}$.

En el curso del vcrano de 1969 , tuvieron igualmente lugar ejercicios en el Atlántico, y sin duda fue de las formaciones que se hallan desplegadas en éste de las que los sovićticos sacaron la tlotilla enviada a Cuba para la fiesta nacional del 26 de julio. Esta fucrza, compuesta de 7 unidades, cntre las que se cuenta un crucero moderno equipado con cohetes ${ }^{80}$, es decir, eventualmente cohetes nucleares, es la primera flota de superficie enviada al Caribe. Se trata pues de un primer paso muy importante. Después de su visita a Cuba, la flotilla soviética permaneció en maniobras en el Gollo de México.

Si cste crucero anuncia la formación, a su debido tiempo, de un destacamento permanente en el Caribe, las consecuencias tanto políticas como militares serian considerables. Procederemos a examinar tales consecuencias al final.

Hasta el presente, las dos operaciones de expansión de importancia estratégica real que se han desarrollado, o están a punto de concretarse, desde hace dos años, conciernen al Océano Indico y al .Mediterráneo.

\section{El Océano Indico}

Hemos visto que la flotá pesquerá soviética habia hecho su primera aparición en el Océano Indico en 1964. El cierre del Canal de Suez en 1967, hizo más dificil la presencia sovićtica. No obstante, en rg68, un destacamento de la flota del Pacifico (un crucero, una fragata lanza-cohetes, un navio antisubmárino) pasó 7 meses realizando un crucero por el Océano

\footnotetext{
${ }^{78} \mathrm{Csis}, \mathrm{sS} \Gamma, \mathrm{p} .6_{4}-65$.
}

$7^{\circ} \mathrm{CSIS}, \mathrm{sSP}, \mathrm{p} .55$.

8n Amunciada el 7 de julio oficialmente por linscú y La Habana, esta llotilla comprende 8 unjlades: L'n crucero lanza-coheles teicdirigidos, dos destructores, dos petroleros, dos submarinos y ull auxiliar de submarinos. 
Alain Jaxe / ¿ Fin de la preponderancịa estratégica uorteamericana?

Indico ${ }^{\prime 2}$. Más tarde, en octubre $y$ diciembre de 1968 respectivamente, dos grupos distintos entraron a su vez en el Océano Indico, el uno provenicnte de Vladivostok, y el otro destacado de las llotas del Norte y' del Báltico, después de haber dado la vuelta a Africa por el Cabo de Buena Esperanza.

\section{CLADRO V}

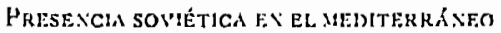

\begin{tabular}{|c|c|c|}
\hline \multirow{3}{*}{ Wayo } & 1954 & - 1 crucero, 2 destructores (en crucero). \\
\hline & 1967 & $\begin{array}{l}\text { - I crucero efeclúa travesia Mar Negro-Leningra- } \\
\text { do-Miar Negro. }\end{array}$ \\
\hline & 1964 & $\begin{array}{l}\text { - Cimmienzo del "destacamento permanemle" de la } \\
\text { flota del Mar. Vegro; } 1.5 \text { barcon diversos. }\end{array}$ \\
\hline Febrero & 1965 & $\begin{array}{l}\text { - } 1 \text { destructor jasa por el Medierráneo para ir a } \\
\text { Eliopia. }\end{array}$ \\
\hline Enero & 1966 & - Segundo crucero a Etiopia. \\
\hline - & & $\begin{array}{l}\text { - El "destacamenlis permane'nte" alcanza, ch lobi5. } \\
\text { 66), } 25 \text { barcos. }\end{array}$ \\
\hline Agosto & 1960 & $\begin{array}{l}\text { - Lin destacamento procedente de Sclastopol se diri- } \\
\text { ge a la República Arabe Linida (RAC). }\end{array}$ \\
\hline \multirow[t]{5}{*}{ Octubre } & 1066 & - Ln segundo destacamento llega a la Rat. \\
\hline & 1967 & $\begin{array}{l}\text { - } 157 \text { navios pasan del . Mar Negro al . Mediterrínco, } \\
\text { scgún fuentes iurcas: }\end{array}$ \\
\hline & & 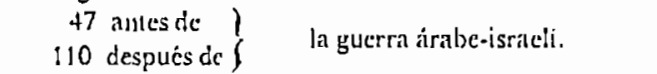 \\
\hline & & 01 regresanal Xar Negro. \\
\hline & & $\begin{array}{l}66 \text { permanecen (de ins cualcs } 2: \text { son minadores. } \\
21 \text { kovak y os., algumos de los cuales son ce- } \\
\text { didos a los egipcios). }\end{array}$ \\
\hline Comierzon de & 1968 & - 45 unidades en permanencia*. \\
\hline Encro & 1968 & $\begin{array}{l}\text { - L'n viaje de inspeccion del Comandante ell Jefe de } \\
\text { la Flota del Mar Negro. }\end{array}$ \\
\hline Septiembre & $\$ 968$ & $\begin{array}{l}\text {-Arribadi del portahelicópteros .Mosken y } 2 \text { destruc- } \\
\text { lores. }\end{array}$ \\
\hline Fines de & 1968 & - LCVINGIRAD. \\
\hline Soviembre de & 1968 & - Visita de uma Пotilla a Casablanca. \\
\hline Comienzo de & 1969 & -70 unidindes. \\
\hline Fines del invierno de & 1969 & -25 unidades. \\
\hline Primavera de & $1961)$ & -60 unjdades. \\
\hline
\end{tabular}

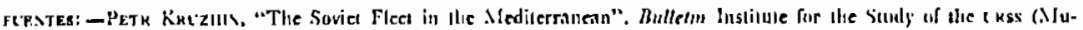

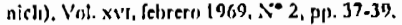
$-\operatorname{csis}, s s)_{1} j^{6}$.

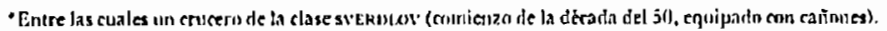

i 2 cruceriss equipados con cohetes

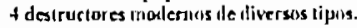

4 destructores antiguis.

15 subma rinos, aigunos de los ruales itucleares (l 6 i 2$)$.

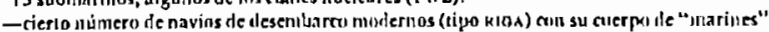

B1 csis, ssp, b2. Hizo estada en Madrás, Bombay, Karashi, Colombo, Basora y Lmm Qasr en Irak, Bandar Abbas en Iruin, Aden y. . Iogadiscio en Somalia. 
ESTUDIOS INTERNACIONALES

El crucero tenia por objetivo la recuperación de una cápsula espacial, y fue asi como entre 24 y 30 navíos soviéticos se encontraban fondeados en la zona de las Seychelles en diciembre. En marzo de 1969 , el número de ćstos descendió a los 12 ó 14 , pero los soviéticos no han vuelto a abandonar el lugar.

\section{El Mediterráneo}

La penctración de la flota soviética en el Mediterráneo no se ha operado de golpe, sino muy progresivamente, siguiendo la cronologia que se da en el cuadro $v$.

En total, se han encontrado en el Mediterráneo, en uno u otro momento las unidades soviéticas señaladas en el cuadro vi.

La cuestión del apoyo aéreo que debe proporcionarse a estas flotas avanzadas se resuelve de dos maneras. La primera consiste en que la zona es cubierta por el radio de acción de los Badgers (Tupolev 16). Partiendo de bases en el Cáucaso, estos aparatos son capaces de alcanzar hasta el fondo del Golfo Pérsico; el Mar Rojo hasta el Yemen (este último excluido); de cubrir la totalidad del territorio de la RAv, la mitad de Libia (comprendido el Golfo de Sirte); Sicilia y el Adriático hasta Trieste. Desde sus bases en Crimea, cubreni inclusive la cuenca occidental hasta poco más allá de Argel y de Barcelona.

La segunda consiste, en que, dado que la presencia soviética es inseparable de la alianza con la RaU y Siria en el conflicto árabe-israeli, la penetración soviética va acompañada de facilidades (instalaciones) en los aeropuertos de estos dos paises, en los que los soviéticos pueden, llegado el momento, pensar en estacionar cazabombarderos Mig 2 I capaces de efectuar, partiendo de Damasco o E! Cairo, misiones de apoyo en la zona oriental de la cuenca oriental, entre Chipre y la frontera de Egipto y Libia.

No obstante, en caso de tensión que haga posible una confrontación con la Sexta Flota de los Estados Unidos, se impondria la puesta a punto de un nuevo aparato con un radio de acción más extenso que los Mig 21 Fishbed y de una utilización más flexible que los Tu-16 Badgers. Los nuevos Mig 23 Foxbat, si estuviesen estacionados en Siria $y$ en Egipto, permitirian cubrir casi toda la cuenca oriental del . Mediterráneo, comprendidos los Dardanelos ${ }^{82}$.

${ }^{92}$ Cf. Mapa de los radiess de acción de los aviones sovićticos, csis, ssp, p. br. 
Alain Joxe / ¿Fin de la preponderancia estratćgica norteamericana?

Cuadro vi

\begin{tabular}{|c|c|c|c|c|}
\hline SUMERO & TIPO & $\begin{array}{l}\text { RECHA DE ENTKADA } \\
\text { EN SERYICAO }\end{array}$ & TONELJE & ARМАMENTO \\
\hline 304 & $\begin{array}{l}\text { Cruccro clase } \\
\text { SVEKDLOV }\end{array}$ & $1951-54$ & 19.300 & Clasico, obsoleto \\
\hline 1 & $\begin{array}{l}\text { Portahelicópterus } \\
\text { MoscL }\end{array}$ & 1967 & $19.000-26.000$ & ism y antiaéren. \\
\hline 8 a 10 & $\begin{array}{l}\text { Fragatas } \\
\text { clase KYiDA } \\
\text { clase KashIX } \\
\text { clase kRUPNi: } \\
\text { Destructures } \\
\text { clase kotuIX }\end{array}$ & $\begin{array}{l}\text { Recientc } \\
\text { Reciente } \\
1960 \\
1955-58\end{array}$ & $\begin{array}{l}6.000 \\
\\
5.500 \\
4.500 \\
3.850\end{array}$ & $\begin{array}{l}\text { 16 cohetes supersini- } \\
\text { cos superficie - super- } \\
\text { ficie atómicos, alcance } \\
600 \mathrm{~km} \text {. } \\
\text { Lucha antiaérea. }\end{array}$ \\
\hline ? & $\begin{array}{l}\text { Navios de desem. } \\
\text { barco modernos } \\
\text { con sus efectivns } \\
\text { de infanteria na- } \\
\text { val. }\end{array}$ & - & - & \\
\hline$?$ & $\begin{array}{l}\text { Buques escolta, } \\
\text { clase sirki }\end{array}$ & - & - & \\
\hline 14 & $\begin{array}{l}\text { Submarinos a la } \\
\text { vez, de los cuales } 1 \\
\text { o } 2 \text { nuclearcs. } \\
\text { Clase } W \\
\text { Clase } Z \\
\text { Clase } R \\
\text { (WV modificados) } \\
\text { Clase } N \\
\text { (propulsión nu- } \\
\text { clear) }\end{array}$ & $\begin{array}{c}1952-58 \\
1956 \\
- \\
- \\
-\end{array}$ & $\begin{array}{l}1.600 \\
2.900 \\
1.600^{*} \\
- \\
-\end{array}$ & \\
\hline
\end{tabular}

=csts, ssP. P. 56 spp.: xp 34:5. p. 15 s4q.

Tales son las condiciones que permiten a la unss prescindir de portaviones en el Mediterráneo. Pero resulta evidente que el problema se desplaza entonces en sentido de la protección de los aeródromos árabes. En general, se considera que la llota soviética del Mediterráneo está lejos de nivelarse con la Sexta Flota norteamericana, pero ello es asi porque se considera el asunto desde el punto de vista del potencial, en los marcos de 
una estrategia militar ofensiva ${ }^{03}$. No existe una preponderancia ofensiva, pero la uRss busca manifiestamente una preponderancia defensiva y disuasiva.

\section{Razones de la expansión de la presencia soviética}

Podemos preguntarnos qué razones impulsan a los soviéticos a afirmar su presencia tan claramente en los tles mares cálidos más "anglosajones" en los últimos años.

Medilerráneo: La explicación soviética, independientemente de la rcivindicación general de igualdad ya mencionada, apareció en forma uniforme en tres artículos publicados en noviembre de 1968 , más o menos

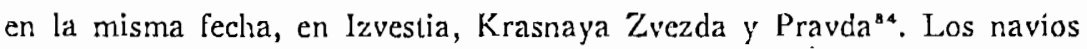
soviéticos entran en el Mediterráneo porque tienen derccho a hacerlo $y$ porque se ven obligados a hacerlo ante la politica reaccionaria de los Estados Unidos.

En este cuadro general de explicación, el objetivo preciso de los soviéticos desde la guerix de $196 \%$, consiste sin duda igualmente en obtener la reapertura del Canal de Suez. Unicamente los grandes buques de carga $y^{\prime}$ los grandes petroleros de las principales compañias de navegación no se ven afectados en absoluto con el desvio del tráfico por el Sur de Africa.

Un articulo de Pravda aparecido en junio de $1969^{85}$ indicaba claramente que la urss considera el bloqueo del Canal como contrario a sus intereses $y$ a los de los paises del tercer mundo, y esto se explica por la importancia reciente de las relaciones comerciales de la Unión Soviética con el Asia Oriental, asi como por la necesidad en que se encuentra de hacer llegar por mar gran parte de su a yuda a! Vietnam.

\section{Océano Indico}

En lo concernicnte al avance hacia el Océano Indico, existe una explicación "histórica" que cs preciso recordar: lạ unss vuelve a

${ }^{83} \mathrm{Cr}$. Com. (R) Robert W. Herrick, autor de Soviet .Vaunl Strategy', en cSis, sSP, p. 125; Carl H. Ammc; ibid., p. 127.

${ }^{84}$ L. Koinsov, "Problema Meditcráneo", Izvestia, 12 de noviembre de !968; Vicealmirante Smirnov (micmbro del Cuartel Gencral del Estado Mayor de la Marina) "Los navios sovićticos en el Mediterránco", Krasnaia Zvezda, 12 de noviembre de ig68; V'. Yermakov, "e! garrote norteamericano cn el Mediterraneo", Pravda, 27 de novicmbre de 1968.

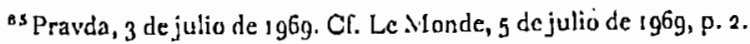


Alain Joxe / ¿Fin de la preponderancia estratégica norteamericana?

hacerse cargo "naturalmente" de los viejos sueños de la politica zarista; esto no es una explicación, sino una simple exposición metafórica. Una interpretación histórica más razonable apela a la tradición propiamente soviética. Es sabida la importancia que Marx concedia a la India en sus análisis del capitalismo inglés. Desde su fundación, la urss ha prestado a la India una atención particular. El único representante de un país dependiente en la Komintern fue el indio Roy, $y$ éste desempeñó un papel de capital importancia en la elaboración de las tesis del Segundo Congreso de la Tercera Internacional sobre "la cuestión nacional y colonial" en 1920. Estas tesis, perfeccionadas en ocasión del Tercer Congreso, que habian de caracterizar durante largo tiempo el pensamiento revolucionario de la Komintern, se basaban esencialmente en un análisis de las condiciones en la India. La fascinación por el subcontinente indio tiene pues sus origenes en la historia propiamente comunista y soviética de Rusia. Hoy dia, la India representa un terreno experimental para el desarrollo de una "democracia nacional" cuya supervivencia y eventual éxito económico contrarrestaria la influencia del modelo chino, que escapa a la influencia soviètica. Puede hablarse por lo tanto de un interés ideológico de la urss en la zona.

Existe, además, otra interpretación complementaria: la de la "atracción del vacio".

El anuncio hecho por los británicos de su próxima retirada del "Este de Suez", ha creado un vacio político. Ahora bien, los Estadós Unidos no tienen intención alguna de venir a colmarle ${ }^{86}$. Por consiguiente, los soviéticos ocupan el lugar.

Para que la explicación sea completa, habria que apoyarse en un análisis preciso de los intereses materiales que la urss puede tener en imponerse en el Sur de Asia. Pero, además, habria que explicar la reticencia de los norteamericanos a ocupar el lugar antes de que lo hagan los soviéticos. Sobre este segundo punto tan sólo pueden darse tres explicaciones.

La primera, es que la guerra de Vietnam impide a los Estados Unidos tomar alguna responsabilidad político-militar nueva lo deseen o no. La segunda es que, con o sin guerra en Vietnam, los Estados Unidos desean en lo sucesivo evitar todo compromiso directo en Asia, a riesgo de replegarse para las tareas estratégicas sobre islotes deshabitados y por consiguien-

${ }^{86}$ Cf. T. B. Millar, The Indian and the Pacific Oceans, Some Strategic Considerations. 
te sin problemas politicos. La tercera, es la hipótesis de un acuerdo tácito entre la urss y los Estados Unidos, tendiente a dejar que se establezcan los soviéticos en la región de la que se retire la Gran Bretaña ${ }^{87}$. Puede tener interés para los Estados Unidos el dejar que la Unión Soviética comprometa su prestigio y sus fuerzas en una zona que le resulta de dificil acceso por mar, $y$ en la cual parece dispuesta a desempeñar el papel de moderador, como lo demostrara en el asunto del conflicto indo-pakistano. Esta zona simbolizaria el interés común ruso-norteamericano contra China, y precisamente asi lo entienden los $\operatorname{chinos}^{88}$.

No es precisamente con alegria que los Estados Unidos vienen permitiendo a la L'Rss que ponga sus plantas en el Medio Oriente desde hace 10 años. La Gran Bretaña abandona el Este de Suez por razones financieras que son el reflejo muy mediatizado de la crisis del sistema de pagos occidentales. Una cooperación tácita soviético-norteamericana en una zona nueva no puede ciertamente compararse a un éxito norteamericano. Cualquiera que sea el valor respectivo de las diversas interpretaciones sobre el avance soviético hacia el sur, todas ellas implican pues, en alguna manera, una retirada aquiescente de los Estados Unidos bajo el efecto de un ligero vuelco en el equilibrio de fuerzas.

\section{La zona del Caribe y la presencia norteamericana en el Mar. Negro}

La última zona sensible en que la c"Rss ha decidido hacer flamear su pabellón es la zona del Caribe. Se ha dicho que la maniobra soviética de julio de

${ }^{87}$ La Unión Soriética, en su avance hacia el Medio Orience y la India, se encuentra a cada instante en una problemática análoga a la de los británicos en el pasado sigio y hasta la guerra mundial (como scĩala C. Gísteg'ger, op. cil.. p. 8). La ruta de las Indias pasa para ellos por la abertura del Canal de Suez, pero también implita la obtención de facilidndes en los puntos de paso obligados, como Singapur (donde ya han establecido una compañia de hercs maritimos), el Yemen, donde ya han ascntado sus pies sólidamente. El estatuto futuro de lus principados del Golfo Pérsico $y$ de Arabia no les deja indiferentes. En lo tocante al Mar Negro, más que trainr de conseguir la revisión de la Convención de Montreux (como lo hizo en 1945 y 1946 ), la Linion Soviética trata ahora de mejorar sus relaciones con Turquia, que tiene derecho at cerrar los estrechos en caso de guerra inminente. La actitud favorable a España tomada con ocasión de las votaciones sobrc Cibraltar en la oxt. más un interés por Malta, tiene su origen en el mismo proyecto de expansión maritima mundial a largo plazo.

${ }^{8} \theta^{\prime}$ Aunque el projecto sovićtico de csiablecimicnto de un sistema de seguridad colectiva en el Sur de Asin, anunciado por Brezhnev en junio $y$ más adehnte por Grom!̣o en su discurso del on de juilo de $19 b 9$, no este según este último "dirigido contra nadie". /Le . Ionde, 12 de julio de big). 
Alain Jwec / ¿Fin de la preponderancia cstratégica norteamericana?

1969 era una respuesta al viaje de Nixon a Bucarest. Es cierto que Rumania se ha separado cada vez más del Pacto de Varsovia en nombre de una oposición al sistema de bloques que fuc proclamada a partir de ig66 y que desembocó en la apertura de relaciones diplomáticas con Alemania Federal en 1967 . El asunto checoslovaco no ha arreglado las cosas, y la garantia declaratoria concedida por Johnson a Rumania en el curso de la crisis de 1968 encuentra hoy dia una especie de consagración en el viaje presidencial. De ahi a pensar que el predominio soviético en el .Mar Negro esté cuestionado ${ }^{89}$, que los navios norteamericanos lanzacohetes que atraviesan desde hace poco los Dardanelos hacia el Norte podrian hallar un dia acogida amigable en los puertos rumanos o que Bucarest podria representar para los Estados Unidos lo que Cuba representa para la URSs, hay una distancia que algunos comentaristas se sienten tentados a franquear, cediendo un poco apresuradamente a la seducción dc las analogias. Cuba intentó en 1959 salir del sistema de los bloques sin romper sus lazos con el "hemisferio" $y$ sin denunciar el pacto de Rio. Rumania "hace lo mismo" con el Pacto de Varsovia, al menos si permanecemos a este nivel verbal de análisis. Pero Rumania no ha hecho una revolución anticomunista popular en el interior, Rumania no depende de la monoexportación de un producto primario, sino que está en plena industrialización. Militarmente, Rumania es de acceso mucho más lácil que Cuba para una fuerza de invasión venida del pais dirigente. El único punto realmente común entre los dos paises con relación a su metrópolis de origen es su proximidad geográlica. La historia y la geografia no se repiten jamás. Establecer una equivalencia entre las dos "posiciones" en sentido militar, es precisamente partir de un punto de vista militar, en un mundo en el que las relaciones politicas y' económicas más sutiles prevalecen sobre la politica de bloques militares.

La presencia de la flota soviética en el Caribe no es más que una de las acciones de la ursS que podrian considerarse como compensaciones al viaje de Nixon a Bucarest (no como respuesta propiamente, y'a que el viaje a La Habana no fue improvisado):

I. Refuerzo de la presencia naval soviética en el Caribe.

2. Reconocimiento de la RDA por la RAC, el 7 de julio.

${ }^{9}$ Gasteyger, Conflicl and Tension in the Mediterrancan, Adelphi Papers, $N^{\circ}{ }^{1}$, septiembre de ig68, p. 6 . 
ESTU DIOS IN T F. R N A C I O N A L E S

3. Nuevo lanzamiento de la propuesta de una desnuclearización del Mediterráneo y manifestación de su buena disposición en cuanto a las negociaciones sobre la limitación de armamentos estratégicos en general.

4. Advertencia velada: según Gromyko, el Pacto de Varsovia, que ha sido fortalecido, vela por la seguridad de los países miembros, $y$ "no permitirá a nadic afectar la seguridad de los países miembros"

Los "movimientos estratégicos" de la Unión Soviética y de los Estados Unidos en los diversos puntos de fricción suscitados en parte por la nueva expansión de la presencia soviética en el mundo, están destinados en la actualidad a reunir y a poner de manifiesto todos los "iriunfos" o "cartas fuertes" de que disponen en este momento ambas potencias sin que pueda tratarse de establecer. equivalencias estrictas entre cada una de las medidas. Esto se explica por la existencia simultánea de tres grandes negociaciones: las negociaciones sobre Vietnam, las negociaciones sobre el Medio Oriente $y^{\prime}$ las negociaciones respecto al nivel de armamentos estratégicos; pero las actitudes tomadas por ambas partes en la actualidad no permiten juzgar de antemano los acuerdos futuros.

\section{Conclusion II}

Los despliegues soviéticos por debajo del nivel nuclear, su potencial pesquero, en materia de exploraciones oceanográfica, de comercio y de presencia naval a gran distancia todavia en sus comienzos, modificarán profundamente el tipo de relaciones internacionales a que estamos acostumbrados desde la guerra fria, puesto que pueden materialmente introducir situaciones de negociación local de un nuevo tipo. Algunos ejemplos: hoy dia, un Arbenz en Guatemala, no sería probablemente derrocado por algunos agentes de la cI৯, porque las relaciones comerciales con la urss habrian sido más importantes mucho antes de que se le pudiera acusar de comunismo, y su aprovisionamiento de armas habria llcgado en un cargamento soviético entre otros muchos. La protección de Cuba puede ser asegurada en forma directa por una fuerza naval capaz de romper una amenaza de bloqueo o de hacer inevitable una confrontación costosa que amenazaria con arrastrar a un conflicto general. La amenaza

${ }^{90}$ Discurso de Gromyko del 10 de julio de 1969 , en la scsión inaugural de la Sexta Sesión del Snviet Supremo. 
Alain Joxe / ¿Fin de la prepondernucin estrniégica nortenmericana?

norteamericana de suspensión de la ayuda militar al Perú ha perdido todo sentido, porque el chantaje de recurrir a los suministros de armas no solamente por parte de Francia sino también por los paises socialistas pesa de una manera completamente nueva en la balanza ${ }^{\circ}$. Mañana, los paises del Este pueden proponer a los peruanos transacciones directas a base de harina de pescado peruana, de la que son consumidores; romper los circuitos comerciaies tradicionales mediante la negociación a nivel gubernamental y encargarse sin dificultades del transporte bajo la protección latente del poderio naval sovićtico. Lo mismo ocurre con otras materias primas en el mundo, estén o no calificadas de "estratégicas" en los reglamentos de la guerra fría.

Existe pues un cambio que se puede intentar ya definir históricamente como el advenimiento de un nucvo equilibrio, no como una ruptura del equilibrio.

\section{CONCLUSIONES GENERAI.ES}

\section{El fin de la preponderancin estralégica norleamericana}

En el curso de estc estudio hemos visto en qué puntos los armamentos, la libertad de acción y las concepciones de los Estados Unidos han dejado de ser predominantes. En resumen, se trata de los puntos siguientes:

En materia de potencial militar, los soviéticos han igualado, o inciuso superado a los Estados Unidos en número de iснм y de mikv desplegados; igualmente en número de submarinos, de lanchas rápidas, de cruceros y' fragatas ultramodernas, de portahelicópteros modernos. Están en vias de llegar a la igualdad en número de submarinos a propulsión nuclear, en progrcsión cualitativa en materia de capacilad de transporte y de intervención anfibia. Descle el punto de vista cualitarivo, los soviéticos han adquirido esa ubicuidad que otrora estuviera reservada a las flotas norteamericanas; han mejorado rápidamente su capacidad de lucha antisubmarina $y$ son superiores a los norteamericanos en edad promedio de sus flotas mercante, pesquera y de gucra.

En maleria de liberlad de acción, los soviéticos han pasado del estado pasivo (reacciones defensivas) al estaclo activo (iniciativa $y$ acciones

${ }^{1} \mathrm{CC}$. Interviú del general Montagne, Primer Ninistro pertano, publicada en Gente (Lima) a ic julio de igfig; El . Mercurio (Santiago) i 1 de julio de ig69, p. 33. 
preventivas) en ocasión de un determinado número de sucesos locales, y" en el plano general de la "maniobra de armamentos".

En 1965, los Estados Unidos llevaron a cabo con éxito, con la "escalnda de los cfectivos" y gracias a su capacidad de transporte aćreo, una opcración de "preemción" defensiva directa que retardó la ofensiva general del Frente Nacional de Libcración contra las ciudades hasta 1968. En 1967 , en el Medio Orientc, se bencficiaron de una "preempcion" ofensiva indirecta, contra el potencial sovićtico, a través de la victoria israeli.

En 1968.69 , los rusos llevaron felizmente a cabo en Vietnam una acción contraofensiva indirecta mediante los suministros de armas ligeras superpotentes al F.LL, que condujo a la actual "escalada de las pérdidas" norteamericanas.

En e! Medio Oriente, los soviéticos refuerzan sus infuencias politicat $y$ militar y modifican los resultados del equilibrio con su flota firmemente comprometida del ládo de los paises árabes; en tanto que la Sexta Flota norteamericana no puedc, sin desgastes politicos extremos, aparccer comprometiéndose al lado de Israel. Con su material "igualador" (Komar y Osa), los soviéticos pueden delegar sus responsabilidades militares al nivel de los golpes de amonestación. La confrontación de los dos grandes localmente no equivalc pues exactamente a una paralización simétrica de los dos grandes ${ }^{92}$, sino a una parálisis major de los Estados Unidos, que carecen de palancas indirectas, despućcs de la victoria de Israel sobre Jordania, y no pueden abrir hoy' dia un segundo frente de intervención directa tipo Vietnam.

En América Latina, mientras que el acuerdo anterior sobre la seguridad de Cuba reposaba sobre el potencial defensivo de la Isla y los compromisos nucleares de la uRss, la defensa del régimen castrista puede igualmente descansar hoy dia en la presencia de unidades navales de superficie nuclearizadas. El efecto politico de la retirada politica de 962 ha sido completamente borrado.

La ukss reivindicará un dia la reapertura del Canal de Suez y quizás el paso por el Cana! de Panamà ${ }^{9}$, sin que la oposición de Estados Unidos

\footnotetext{
92 Gasteyger, op. cil., p. 15.
}

${ }^{03} \mathrm{No}$ hay ninguna causa cxplicita que impida el "paso inocente" de una Mola soviética por el Cana! de Panamá, pero la zona del canal es zona miliar y las acciones de la Compañia del Cana! pertenecen todas al Mlinisterio norteamericano de Defensa. Cr. R. R. Baxier, Vias acuóticas internacionales, . México, Unión Grálica rgb̈7. 
Alain Jnxe / ¿Fin de la preponderancin estmiegica norteamericana?

pueda fundarse en otra cosa que la petición expresa de un reparto de las zonas de influencia.

La urss tiene la iniciativa en la reapertura de la carrera de armamentos en los sistemas de armas. siguientes: $\triangle \mathrm{HM}_{\mathrm{M}}$, FOBS, M:RV, submarings nucieares, flota ultramoderna de superficie. Sin duda no aceptarả frenar en todos estos puntos sin concesiones nurtcamericanas, y cxisten pocas posibilidades en especial de que acepte limitación alguna de los armamentos navales en la coyuntura actual, cuando se halla a punto de alcanzar la igualdad con los Estados Unidos ${ }^{94}$.

Concepciones estratégicas. El fin de la preponderancia norteamericana se traduce por ĺa desaparición del lenguaje de la amenaza y de la disuasión nuclear y la reintroducción del "lenguaje de las cañoncras".

En este dominio, no existe pura imitación del modelo norteamericano de intervención, sino creación original de los soviéticos: la flota "in being", centrada en torno a los submarinos de ataque $y$ sin portaviones, y cujo apoyo aéreo depende estrechamente de la cxistencia de un apoyo politico local (en tanto que el portaviones supone por cl contrario que se trata de vencer la hostilidad local). Se trata de una sintesis original entre la acción a larga distancia y la tradición soviética de operaciones navales muy' estrechamente combinadas con las operaciones terrestres.

La originalidad del sistema de armas navales sovićticas actual posec igualmente una significación politica: renunciar a la ausencia de portaviones significaria para los soviéticos adoptar una estrategia de intervención liberada eventualmente de la obligación de un apojo politico continental, es decir, darse ios medios de una politica de intervención desconectada de la existencia en la región de una "guerra justa" (guerra de liberación nacional) y de un aliado que disponga de un territorio, o dicho de otro modo, adoptar el modelo nortcamericano, lo que, por el momento, se guardan de hacer. En los tres aspectos que definiamos en la introducción puede decirse pues, con cierta exactitud, que la preponderancia estratégica de los Estados Unidos ha cesado de mani festarse.

${ }^{4}$ Opinión del almirante (R) Gcorge W. Anderson Jr., antiguo Jefe de Operaciones Navales en la época de la crisis cubam de 1962 , que chocó en la época con .Meivanarn y no cesi de mostrarse hostil a la estrategia que ha conducido a la sisuación actual. Cr. su contribución a csis, SSP, p. 121. 


\section{Un desquile de la crisis cubana de 1962}

Después de todo, el equilibrio soviético-norteamericano ha existido siempre, dado que a pesar de la desigualclad de las fuerzas al final de la Segunda Guerra Mundial, la guerra ruso-norteamericana no se ha producido.

El equilibrio estratćgico bajo Stalin y hasta Jruschov, descansaba en una desigualdad más una asimetria: la superioriclad de las tropas convencionales soviéticas en Europa contrapesaban el monopolio nuclear norteamericano, haciendo de Europa el rehén de la urss. Pero se trataba en el fondo de un equilibrio regional, porque la urss limitaba sus ambiciones y su influencia real a sus zonas fronterizas.

El actua! reajuste del equilibrio se preparaba desde hace varios años.

Con Jruschov y la era de los primeros cohetes, el crecimiento hasta alcanzar la escala mundial (mundialización) de las ambiciones concretas de la urss alraviesa una fasc juvenil, por decirlo asi, a imagen y semejanza del optimismo chabacano y cmbrollador de! antiguo Secretario del pC soviético. La superioridad definitiva del sistema socialista sobre el sistema capitalistá es proclamada urbi el orbi, pero los medios maleriales de la Unión Soviética están aún lejos de equilibrar realmente las fucrzas siempre crecientes del "imperio norteamericano". Se asiste entonces a actos ligeramente aventurados, como la intromisión en el asunto congolés y sobre lodo la cuestión cubana de 962 , que pueden definirse de la mancra siguicnte: la urss trala de sacar partido de la fuerza nuclear cquilibradora que le daria la instalación en Cuba de un potencial nuclear. La retirada soviética da la imagen de ia relación de fucrza real, a escala global y local, pero no deja incrme a Cuba: este pais se encuentra después de la crisis con que es la principal potencia militar del continente después de Estados Unidos, y la invasión cle la isla se convierte en una operación demasiado cara para que vuelva a pensarse en clla de ahi en adelante.

La crisis hace reflcxionar: del lado de los Estados Unidos, se desculure que el empleo de la amenaza es rentable y que la urss es respetable pero menos fuerte de lo que se pensaba. Se lanzan a la guerra de Vietnam con la fe puesta en un modelo de escalada que habia sido construido para crisis del ipo cubano. Del laclo sovictico, durante siete años, los miliares $\dot{y}$ los burócranas morosos que suceden a Jruschov organizan una verdadera fucrza a la vez que aceptan las afrentas, como el bombardeo de Victnam del Norte, sin dejarse provocar. 
La coyuntura actual constituye pues en cierto modo el desquite de la crisis cubana de 1962 . El crecimiento rápido de los ıсвм del año último es comparable al transporte rápido de los cohetes soviéticos a Cuba, pero sin "aventurerismo estratégico" y sin posibilidades de "capitulacionismo táctico", las dos herejías notorias que los chinos habian censurado con justicia en la iniciativa de 1962 . El cisma con China ha llegado a convertirse en la oposición irreductible entre Estados porque la orientación "revisionista" de la urss, su esquema del paso pacifico al socialismo no ha hecho otra cosa que reforzarse en proporción a su poderio. Empero, si el equilibrio nuclear ha sido realmente alcanzado, cntramos, lo qucramos o no, en el fin del "fctichismo nuclear" que caracterizaba tanto a los norteamericanos (fetichismo del más fuerte) como a los soviéticos (Retichismo del más débil) en el momento en que se echaban las bases del cisma chino-soviético.

Los "movimientos" no nuclearés vuclven a constituirse en la base del lenguaje de la diplomacia armada, y el lenguaje nuclear, que fuera inventado por los Estados Unidos, queda pasado de moda. Los soviéticos han logrado con éxito volver a imponer el lenguaje de las cañoneras, evitando a la vez ser acorralados hacia la astixia económica que los Estados Unidos se proponian hacerles sufrir en la carrera nuclear.

La cuestión que se plantea de aqui en adelante es saber si este nuevo equilibrio introducido por el fin de la preponderancia norteamericana en los diversos dominios que definiéramos al principio desemboca o no en un reparto del mundo en zonas de influencia.

\section{¿Zonas de influencia o imbricación universal?}

Los movimientos registrados recientemente por parte de los dos grandes pueden ser considerados como el cebo de un reparto en zonas de influencia, pero contienen igualmente en germen la negación de todo reparto zonal y la perspectiva de una compenetración estrecha y de una marqueteria de alianzas complejas sin relación con la contingencia geográfica.

Con el primer modelo debe relacionarse el avance de la uRss sobre su flanco sur, la influencia cada vez más clara sobre el mundo árabe y musulmán en general, la constitución de la India en zona neutralizada, la falta de autonomia de Europa occidental, la invasión de Checoslovaquia y la persistencia del aisiamiento latinoamericano. Con el segundo modelo, la 
E S T U D I O S I N T E R N A C I O N A L E S

expedición de Nixon a Rumania, el crucero de la flota soviética por el Caribe; y no se debe a la casualidad que en estos dos paises (es decir Rumania y Cuba) China desempeña, en segundo plano, política o ideológicamente un papel especial. En último análisis, la solución del reparto en zonas de influencia será probablemente impracticable prečisamente porque los dos grandes no son dos, sino quë pretenden ser solamente dos mientras ello es todavia posible. La presencia de China introduce en la lógica de las negociaciones globales una variable independiente que hace casi imposible un nuevo acuerdo de Yalta en gran escala, temido recientemente por el Mariscal Tito; también lo impediria una acción politica más determinada de Europa y Japón. En el mundo de los Tres Grandes, las alianzas más sorprendentes se hacen practicables y la fluidez de las coaliciones de intereses nos evitará sin duda desembocar en ese statu quo definitivo soñado por los unos y temido por los otros, en el cual las posibilidades de cambios estructurales rápidos se verian inmovilizadas durante largo tiempo en ciertos paises subdesarrollados.

Julio $: 969$ 